\title{
Endogenous Dopamine Regulates the Rhythm of Expression of the Clock Protein PER2 in the Rat Dorsal Striatum via Daily Activation of $\mathrm{D}_{2}$ Dopamine Receptors
}

\author{
Suzanne Hood, Pamela Cassidy, Marie-Pierre Cossette, Yuval Weigl, Michael Verwey, Barry Robinson, Jane Stewart, \\ and Shimon Amir \\ Center for Studies in Behavioral Neurobiology/Groupe de Recherche en Neurobiologie Comportementale, Department of Psychology, Concordia University, \\ Montreal, Quebec H4B 1R6, Canada
}

A role for dopamine (DA) in the regulation of clock genes in the mammalian brain is suggested by evidence that manipulations of DA receptors can alter the expression of some clock genes outside the suprachiasmatic nucleus (SCN), the master circadian clock. The role of endogenous DA in the regulation of clock gene expression is unknown. Here, we demonstrate a direct relationship between extracellular DA levels and the rhythm of expression of the clock protein PERIOD2 (PER2) in the dorsal striatum of the male Wistar rat. Specifically, we show that the peak of the daily rhythm of extracellular DA in the dorsal striatum precedes the peak of PER 2 by $\sim 6 \mathrm{~h}$ and that depletion of striatal DA by 6-hydroxydopamine or $\alpha$-methyl-para-tyrosine or blockade of $\mathrm{D}_{2}$ DA receptors by raclopride blunts the rhythm of striatal PER2. Furthermore, timed daily activation of $D_{2} D A$ receptors, but not $D_{1}$ DA receptors, restores and entrains the PER2 rhythm in the DA-depleted striatum. None of these manipulations had any effect on the PER2 rhythm in the SCN. Our findings are consistent with the idea that the rhythm of expression of PER2 in the dorsal striatum depends on daily dopaminergic activation of $\mathrm{D}_{2} \mathrm{DA}$ receptors. These observations may have implications for circadian abnormalities seen in Parkinson's disease.

\section{Introduction}

Circadian rhythms of physiology and behavior are generated by a core set of clock genes, which regulate their own expression in a $24 \mathrm{~h}$ transcriptional-translational feedback cycle (for review, see Reppert and Weaver, 2001; Ko and Takahashi, 2006). Among these genes, Period2 (Per2) plays a critical role in the regulation of this $24 \mathrm{~h}$ rhythm by serving as the interface between the negative and positive limbs of the cycle (Chen et al., 2009).

In mammals, the master circadian clock resides in the suprachiasmatic nucleus (SCN), and the phase of rhythmic clock gene expression in this region is entrained by environmental light (Lowrey and Takahashi, 2000). Rhythmic clock gene expression is not limited to the SCN, however, and has been characterized in several other regions of the brain and in peripheral tissues (Abe et al., 2002; Shieh, 2003; Amir et al., 2004; Lamont et al., 2005; Guilding and Piggins, 2007). It is believed that these rhythms in clock gene expression serve to control, in a tissue-specific manner, daily variations in cellular and metabolic activity and functional output. Although signals from the SCN are required to maintain and coordinate rhythmic gene expression in the brain and periphery, these extra-SCN rhythms can also be influenced

\footnotetext{
Received April 26, 2010; revised Aug. 27, 2010; accepted Aug. 27, 2010.

This work was supported by grants from the Canadian Institutes of Health Research, le Fonds de la Recherché en Santé Québec, and the Concordia University Research Chair Program.

Correspondence should be addressed to Shimon Amir, Center for Studies in Behavioral Neurobiology, Concordia University, 7141 Sherbrooke Street West, SP-244, Montreal, Quebec H4B 1R6, Canada. E-mail: shimon.amir@concordia.ca.

DOI:10.1523/JNEUROSCI.2128-10.2010

Copyright $\odot 2010$ the authors $\quad 0270-6474 / 10 / 3014046-13 \$ 15.00 / 0$
}

independently by a variety of other signals, including steroid hormones, stressors, and restricted feeding schedules (Takahashi et al., 2001; Wakamatsu et al., 2001; Perrin et al., 2006; Segall et al., 2006; Angeles-Castellanos et al., 2007; Amir and Stewart, 2009; Verwey and Amir, 2009).

Increasing evidence suggests that the neurotransmitter dopamine (DA) may be involved in the regulation of extra-SCN clock gene expression. In particular, activation of $\mathrm{D}_{2}$ receptors has been demonstrated to modulate the circadian effects of light on locomotor activity in mice (Doi et al., 2006) and to regulate expression of clock genes in the retina (Besharse et al., 2004; Yujnovsky et al., 2006) and striatum (Imbesi et al., 2009; Sahar et al., 2010), a region important for motor control, learning, cognition, and reward. There is no direct evidence, however, that endogenous DA regulates rhythmic expression of clock genes. To study this, we characterized the rhythm and the cellular expression of the clock protein PERIOD2 (PER2) in the dorsal striatum, a region richly innervated by dopaminergic projections from the substantia nigra. Furthermore, we examined the relationship between the circadian rhythms of locomotor activity, extracellular DA level, and PER2 expression in this region. To determine the role of endogenous DA in the regulation of PER2 expression in the dorsal striatum, we depleted DA or blocked activity at DA receptors by using unilateral 6-hydroxydopamine (6-OHDA) lesions of the medial forebrain bundle (MFB), injections of the tyrosine hydroxylase inhibitor $\alpha$-methyl-para-tyrosine (AMPT), or continuous infusions of selective $\mathrm{D}_{1}$ or $\mathrm{D}_{2}$ DA receptors antagonists. Finally, we studied the effect of $\mathrm{D}_{1}$ and $\mathrm{D}_{2 / 3}$ DA receptor agonists, delivered either by timed daily injection or continuously via os- 
motic minipump, on the rhythmic expression of PER2 in the dorsal striatum of 6-OHDA-lesioned or intact rats. Our results establish endogenous DA, acting via $\mathrm{D}_{2} \mathrm{DA}$ receptors, as a regulator of PER2 rhythms in the dorsal striatum.

\section{Materials and Methods}

Subjects. A total of 172 male Wistar rats (Charles River), weighing 300 $\mathrm{g}$ at the start of each experiment, was used. Rats were housed singly in shoebox cages equipped with running wheels and kept in individual lightproof and sound-attenuated cabinets. Within each cabinet, an overhead fluorescent tube provided light on a $12 \mathrm{~h}$ light/dark (LD) cycle (light intensity within the cage was $\sim 300$ lux) and wheel-running activity was monitored continuously by computer using VitalView software (Minimitter). Rats used in the AMPT experiment were housed singly in plastic shoebox cages, but without running wheels, and were kept in a private room with a $12 \mathrm{~h} \mathrm{LD}$ cycle (lights on at 8:00 A.M.). Throughout all experiments, rats had ad libitum access to laboratory chow (Purina) and tap water. Rats were left in their home cages for at least $10 \mathrm{~d}$ to entrain to the $\mathrm{LD}$ cycle before the start of each experiment and were randomly assigned to an experimental condition. All experimental procedures followed the guidelines of the Canadian Council on Animal Care and were approved by the Animal Care Committee of Concordia University.

Drugs. 6-OHDA (Sigma-Aldrich) was prepared in a concentration of 2 $\mu \mathrm{g} / \mu \mathrm{l}$ in physiological saline containing $0.5 \%$ ascorbic acid. Desipramine hydrochloride, quinpirole hydrochloride, 6-chloro-1-phenyl-2,3,4,5tetrahydro-1 $\mathrm{H}$-3-benzazepine-7,8-diol (SKF 81297), AMPT, 7-chloro3-methyl-1-phenyl-1,2,4,5-tetrahydro-3-benzazepin-8-ol (SCH 23390), and raclopride tartrate were purchased from Sigma-Aldrich and were dissolved in distilled water.

Intracranial cannulation for in vivo microdialysis. Rats were anesthetized using a mix of ketamine (Ketaset; $90 \mathrm{mg} / \mathrm{kg}$, i.p.; Ayerst) and xylazine (Rompun; $10 \mathrm{mg} / \mathrm{kg}$, i.p.; Bayer). Bilateral cannulae (21 gauge, 8.1 $\mathrm{mm}$ below pedestal; Plastics One) were implanted in the dorsal striatum using the following stereotaxic coordinates: posterior (from bregma), $-0.1 \mathrm{~mm}$; medial/lateral, $3.4 \mathrm{~mm}$; ventral (from skull surface), -3.0 $\mathrm{mm}$. Cannulae were secured to the skull surface using dental acrylic. As a postoperative treatment, rats were given $2 \mathrm{ml}$ of saline with $2 \mathrm{mg} / \mathrm{kg}$ ketoprofen (Anafen; Merial) subcutaneously and $0.15 \mathrm{ml}$ of Procillin (penicillin G; 150,000 I.U.; Bayer) intramuscularly.

Unilateral 6-OHDA lesion. One hour before surgery, rats were injected intraperitoneally with desipramine $(2.5 \mathrm{mg} / \mathrm{kg})$ to protect noradrenergic fibers from the 6-OHDA toxin. Rats were then anesthetized using a mix of ketamine and xylazine, and a unilateral injection of $8 \mu \mathrm{g}$ of 6-OHDA was made over $8 \mathrm{~min}$ into either the right or left MFB (counterbalanced across rats) using the following stereotaxic coordinates: posterior (from bregma), $-3.0 \mathrm{~mm}$; medial/lateral, $\pm 1.4 \mathrm{~mm}$; ventral (from skull surface), $-8.2 \mathrm{~mm}$. After the infusion of the toxin, the injector was left in place for $1 \mathrm{~min}$ and then was slowly raised over $3 \mathrm{~min}$. Ketoprofen (2 $\mathrm{mg} / \mathrm{kg}$ ) and $0.15 \mathrm{ml}$ of Procillin were given postoperatively. The extent of the lesion was confirmed postmortem with immunohistochemical staining for expression of the dopamine transporter (DAT).

Osmotic minipump surgery. Osmotic minipumps (Alzet model 2ML2; Durect) were implanted to deliver a constant $24 \mathrm{~h}$ infusion of SCH 23390 , raclopride, quinpirole, or SKF 81297. The pumps were filled according to the manufacturer's instructions and were left in $0.09 \%$ saline for $24 \mathrm{~h}$ before implantation. Rats were anesthetized using isoflurane (Vetoquinol NA), and a small incision was made between the scapulae. Using a hemostat, a small pocket was created under the skin into which a pump was inserted with the flow moderator pointing away from the incision site. The incision was then closed with wound clips. For rats in the sham surgery group, the same surgical procedure was followed but no pump was inserted.

Immunohistochemistry. At the end of each experiment, rats were given an overdose of sodium pentobarbital (Somnotol; $100 \mathrm{mg} / \mathrm{kg}$ ) at their assigned zeitgeber time (ZT) (where ZT1 indicates $1 \mathrm{~h}$ after lights on and ZT13 $1 \mathrm{~h}$ after lights off) and perfused intracardially with $300 \mathrm{ml}$ of cold $0.09 \%$ saline, followed by $300 \mathrm{ml}$ of cold $4 \%$ paraformaldehyde in $0.1 \mathrm{M}$ phosphate buffer. Brains were extracted and kept in $4 \%$ paraformaldehyde solution overnight at $4^{\circ} \mathrm{C}$, and then sliced with a vibratome into $50 \mu \mathrm{m}$ coronal sections. Sections were stored in Watson's cryoprotectant (Watson et al., 1986) at $-20^{\circ} \mathrm{C}$ until immunohistochemistry was performed.

Immunohistochemical staining for PER2- and PERIOD1 (PER1)immunoreactive (IR) nuclei was performed according to protocols described previously (Amir et al., 2004; Verwey et al., 2009). PER2 antibodies were obtained from ADI (polyclonal rabbit primary antibody; concentration, 1:1000) and Santa Cruz Biotechnology (polyclonal goat primary antibody; concentration, 1:4000). We found no differences between these primary antibodies in the pattern or amount of staining for PER2 in a number of different brain regions. PER1 primary antibody (concentration, 1:24,000) was a generous gift from Dr. S. M. Reppert (University of Massachusetts Medical School, Worcester, MA). The specificity of the PER2 and PER1 primary antibodies was previously confirmed with blocking experiments, in which addition of the PER2 peptide or the PER1 peptide ( $1 \mu \mathrm{g} / \mathrm{ml}$ in PBS) to the primary incubation solution prevented staining of PER2 or PER1 expression, respectively, in the tissue (Hastings et al., 1999; Field et al., 2000). Staining for DAT was performed with a monoclonal antibody raised in rat (1:1500; Millipore) in Triton TBS containing $2 \% \mathrm{NGS}$ for $40 \mathrm{~h}$ at $4^{\circ} \mathrm{C}$, an anti-rat secondary (1:500; Millipore) for $1 \mathrm{~h}$ at $4^{\circ} \mathrm{C}$, and an avidin-biotin peroxidase solution for $2 \mathrm{~h}$ at $4^{\circ} \mathrm{C}$ (Vectastain Elite $\mathrm{ABC}$ kit; Vector Laboratories). Sections were then rinsed in a $0.5 \%$ 3,3-diaminobenzidine (DAB) solution, and IR nuclei were visualized with a solution containing $0.5 \% \mathrm{DAB}, 0.1 \% \mathrm{H}_{2} \mathrm{O}_{2}$, and $8 \% \mathrm{NiCl}_{2}$. All sections were mounted on gelatin-coated slides, dehydrated in a series of alcohols, and cleared in Citrisolv. Glass coverslips were secured with Permount.

Microscopy. Stained brain sections containing the dorsal striatum and SCN were examined under a light microscope using a $20 \times$ objective, and $400 \times 400 \mu \mathrm{m}$ images of each region were captured using a Sony XC-77 video camera, a Scion LG-3 frame grabber, and Image SXM software (version 1.8; S. D. Barrett, University of Liverpool, Liverpool, UK; http:// www.ImageSXM.org.uk). Images of the right and left dorsal striatum were taken in the upper lateral quadrant from five to six sections between approximately + anterior/posterior $(+\mathrm{a} / \mathrm{p}) 0.4 \mathrm{~mm}$ (from bregma) and the junction of the anterior commissure (approximately $-\mathrm{a} / \mathrm{p} 0.2 \mathrm{~mm}$ from bregma). Images of the right and left SCN were taken from five to six representative sections. The number of PER2- or PER1-IR nuclei was then counted in each image. The mean number of IR nuclei in the right and left SCN and dorsal striatum was calculated for each subject from the four images having the highest number of labeled nuclei out of all the images taken of that structure in a given hemisphere.

We also examined the pattern of PER2 expression in images taken from the medial part of the striatum in the same sections, as well as the lateral and medial regions of sections that were posterior to the junction of the anterior commissure. We found that the rhythms of PER2 expression were consistent across these regions and that the effects of each experimental manipulation on their expression did not vary within the striatum. As such, we report here only the data from the dorsolateral region of anterior striatal sections.

Quantitative real-time PCR. Two weeks after receiving a unilateral injection of either 6-OHDA or vehicle into the MFB, rats were decapitated at either ZT7 or ZT19 and brains were extracted, flash-frozen using cooled 2-methylbutane, and stored at $-80^{\circ} \mathrm{C}$. Brains were later sectioned on a cryostat at $200 \mu \mathrm{m}$ and punches of the right and left striatum were taken. Striatal tissue samples were sonicated and total RNA was isolated from striatal punches using an RNAqueous-Micro kit (Ambion). RNA samples were treated with DNase 1 to remove any traces of DNA. Briefly, $20 \mu \mathrm{l}$ of the RNA sample were incubated together with $2 \mathrm{U}$ of DNase 1 at $37^{\circ} \mathrm{C}$ for $30 \mathrm{~min}$. Two microliters of DNase inactivation reagent was added at room temperature for $2 \mathrm{~min}$ to stop the enzyme reaction. The treated RNA was recovered after a 90 s centrifugation at $17,000 \times g$. The RNA integrity profile of each sample and its concentration were assessed using an Agilent RNA6000 Nanokit (Agilent Technologies) and 2100 Bioanalyzer electrophoresis (Agilent). A Nanodrop2100c spectrophotometer (Thermo Fisher Scientific) was used to measure the $260 / 280$ and $260 / 230$ ratios for assessment of DNA and protein contamination. 
Total RNA ( $1 \mu \mathrm{g}$ per sample) was reverse transcribed using the HighCapacity cDNA Reverse Transcription kit with RNase inhibitor (Applied Biosystems) according to manufacturer's instructions. Briefly, a 2XRT master mix containing reverse transcription (RT) buffer, deoxyribonucleotide triphosphate mixture, random primers, MultiScribe RT enzyme, and RNase inhibitor was added to the total RNA sample. Forty microliter sample reactions were incubated at $25^{\circ} \mathrm{C}$ for $10 \mathrm{~min}$, followed by $37^{\circ} \mathrm{C}$ for $2 \mathrm{~h}$ and $85^{\circ} \mathrm{C}$ for $5 \mathrm{~min}$ in a CFX96's C1000 Thermal Cycler chassis (Bio-Rad). Negative controls of the RT reaction were performed in parallel by omitting the RT enzyme or by substituting the RNA for nucleotide-free water to exclude any DNA and RNA contamination. The cDNA library samples were stored at $-20^{\circ} \mathrm{C}$.

rPer2 expression was determined by using the custom-designed PerfectProbe Gene Detection kit (PrimerDesign) (sense primer, 5' ${ }^{\prime}$-TTC CAC CAG CAA CCC CAA A-3'; antisense primer, 5' -CAG GAG TTA TTT CAG AGG CAA GT-3'; probe, $5^{\prime}$-FAM-CTT CCC CAG CCA GCC TCA CTT TCC Ggg aag- $3^{\prime}$ ). PCRs were performed on the CFX96 RealTime PCR Detection System (Bio-Rad) with an annealing temperature of $50^{\circ} \mathrm{C}$. A standard curve, established using a series of five fourfold dilutions (0.39-100 ng range), was used to evaluate amplification efficiency of the target gene. NRT and negative controls were also run to exclude DNA and RNA contamination. cDNA samples were tested in triplicate. The expression level in each sample was normalized relative to the sample with the highest expression value. Samples were then compared using the $2^{-\Delta \mathrm{Ct}}$ method.

In vivo microdialysis for extracellular DA levels in the dorsal striatum. In vivo microdialysis sampling was performed in custom-made Plexiglas chambers $\left(42 \times 39 \times 33.5 \mathrm{~cm}^{3}\right)$ with stainless-steel rod floors. Each chamber was housed individually in a plywood cabinet. An overhead fluorescent tube in each cabinet provided light on a $12 \mathrm{~h} \mathrm{LD}$ schedule that was the same as that maintained in the rats' home cages. Food and water were available ad libitum. Microdialysis probes were custom made. Their construction has been described previously (Sorge et al., 2005).

Sampling procedure. After stereotaxic surgery, rats remained in their home cages for a 1 week recovery period during which they were handled daily. One day before in vivo microdialysis sampling began, rats were moved from their home cages to the sampling chambers to habituate them to the sampling environment. The dialysis probes were inserted into the rats' heads $\sim 6 \mathrm{~h}$ before dialysate sampling began. Artificial CSF $\left(145 \mathrm{mM} \mathrm{Na}^{+}, 2.7 \mathrm{~mm} \mathrm{~K}^{+}, 1.2 \mathrm{~mm} \mathrm{Ca}^{2+}, 1.0 \mathrm{mM} \mathrm{Mg}^{2+}, 150 \mathrm{mM} \mathrm{Cl}^{-}, 0.2\right.$ $\mathrm{mm}$ ascorbic acid, $2 \mathrm{~mm} \mathrm{Na}_{2} \mathrm{HPO}_{4}$, pH $7.4+0.1$ ) was perfused during this period at a rate of $0.5 \mu \mathrm{l} / \mathrm{min}$ to prevent the probes from blocking. Beginning $8 \mathrm{~h}$ after the lights turned off, or ZT20, the flow rate was increased to $1 \mu \mathrm{l} / \mathrm{min}$ and dialysate samples were collected from both the right and left hemispheres of each rat every $30 \mathrm{~min}$ for a full $24 \mathrm{~h}$ period. Samples were frozen on dry ice and kept at $-80^{\circ} \mathrm{C}$ until analysis using HPLC.

Analysis of DA content in striatal tissue samples from the dorsal striatum. To quantify the depletion of DA in the dorsal striatum after AMPT treatment, rats were decapitated and brains were flash-frozen using cooled 2-methylbutane. Brains were later sectioned on a cryostat at 300 $\mu \mathrm{m}$, and $1 \mathrm{~mm}$ punches of the right and left anterior dorsal striatum were taken from a single section for each rat (approximately $+\mathrm{a} / \mathrm{p} 0.4$ from bregma). The preparation of striatal tissue samples and extraction of supernatant has been described previously (Moroz et al., 2004).

HPLC. To assay for DA content, samples ( $10 \mu \mathrm{l}$ in the case of dialysate, or $5 \mu \mathrm{l}$ in the case of tissue punch supernatant) were analyzed according to a previously described protocol (Moroz et al., 2004). Extracellular levels of DA measured from in vivo microdialysis samples are expressed as picograms of DA per microliter of dialysate. The amount of DA content measured in striatal tissue punches is expressed as picograms of DA per microgram of insoluble material.

Statistical analyses of IR nuclei counts and Per2 transcription levels. In the experiments involving unilateral injections of 6-OHDA toxin into the $\mathrm{MFB}$, data were analyzed only from those rats with complete unilateral lesions, as confirmed by an absence of DAT staining in the dorsal striatum ipsilateral to the 6-OHDA injection. Differences in PER2- or PER1-IR nuclei or relative Per2 mRNA expression levels were analyzed using mixed-model ANOVA with ZT and drug treatment group as between-subjects factors and hemisphere as a within-subjects factor. Differences in PER2 expression in experiments using AMPT, the chronic DA receptor antagonists, and injections of DA receptor agonists in naive rats were analyzed using two-way ANOVA with ZT and treatment group as between-subjects factors. $\alpha$ level was set at 0.05 for all tests. Significant interactions were analyzed further using one-way ANOVA and Bonferroni-corrected post hoc comparisons, or $t$ tests where appropriate.

Analysis of wheel-running activity rhythms. Mean wheel-running activity during the $12 \mathrm{~h}$ light and $12 \mathrm{~h}$ dark phases was calculated for the last week of the entrainment period, the second week after the 6-OHDA lesion surgery, and the $10 \mathrm{~d}$ period of treatment with SKF 81297 or quinpirole (daily injections or chronic treatment via minipump). The effect of the 6-OHDA lesion surgery on the rhythm and amplitude of wheel-running activity was analyzed using separate repeated-measures ANOVA with stage of experiment (entrainment and postlesion surgery) or phase (light and dark) as within-subjects factors. The effects of SKF 81297 and quinpirole treatment on the amount of wheel running in the light and dark phases were analyzed using separate one-way ANOVA, and a repeated-measures ANOVA was used to evaluate the rhythm of activity across the light and dark phases. The $\alpha$ level was set at 0.05 for all analyses. Significant group differences were followed up with Bonferroni-corrected post hoc comparisons.

\section{Results}

\section{Phase relationship between locomotor activity, PER2} expression, and extracellular DA levels in the dorsal striatum To study the relationship between PER2 expression in the dorsal striatum and changes in extracellular DA levels in this region, we first examined the rhythm of PER2 in naive rats housed in a normal $12 \mathrm{~h}$ LD cycle. After a $10 \mathrm{~d}$ entrainment period, rats were killed at $4 \mathrm{~h}$ intervals over $24 \mathrm{~h}$ beginning $1 \mathrm{~h}$ after lights on, or ZT1, and brain sections containing the dorsal striatum and SCN were stained for PER2 expression using immunohistochemistry. The daily rhythm of PER2 expression in the dorsal striatum and SCN is illustrated in representative images in Figure 1, and the mean number of PER2-IR nuclei at each sampling time is shown in Figure 2, $a$ and $b$. As can be seen from Figures 1 and $2 a$, the rhythm of PER2 expression in the dorsal striatum peaks in the morning, at the beginning of the light phase (ZT1), and reaches its trough in the evening, at the beginning of the dark phase (ZT13). In the SCN, the rhythm of PER2 expression peaks in the evening, in antiphase to that in the dorsal striatum (Figs. 1, 2b).

Using in vivo microdialysis, we then measured extracellular DA levels in the dorsal striatum of three rats over $24 \mathrm{~h}$. As shown in Figure $2 c$, extracellular DA levels in the dorsal striatum (expressed as picograms of DA/microliter of dialysate) fluctuate in a circadian rhythm falling during the light phase and peaking in the middle of the dark phase. Thus, this rhythm of extracellular DA levels in the dorsal striatum, while resembling the PER2 rhythm in the SCN, is significantly out of phase with the PER2 rhythm in the dorsal striatum.

To illustrate the temporal relationship between the rhythms of PER2 expression, extracellular DA levels in the dorsal striatum, and wheel-running activity, Figure $2 d$ shows the $24 \mathrm{~h}$ pattern of wheel running in those rats killed for PER2 immunohistochemistry. As in the case of striatal levels of DA, wheel-running activity occurs primarily in the dark phase and is absent during the light phase. Thus, the rhythms of PER2 expression in the SCN, extracellular DA levels in the dorsal striatum, and wheel running are in phase with one another, but are in antiphase to the rhythm of PER2 expression in the dorsal striatum.

\section{PER2 expression after unilateral 6-OHDA lesion}

To determine whether changes in endogenous levels of DA would affect the normal rhythm of PER2 in the dorsal striatum, we made 

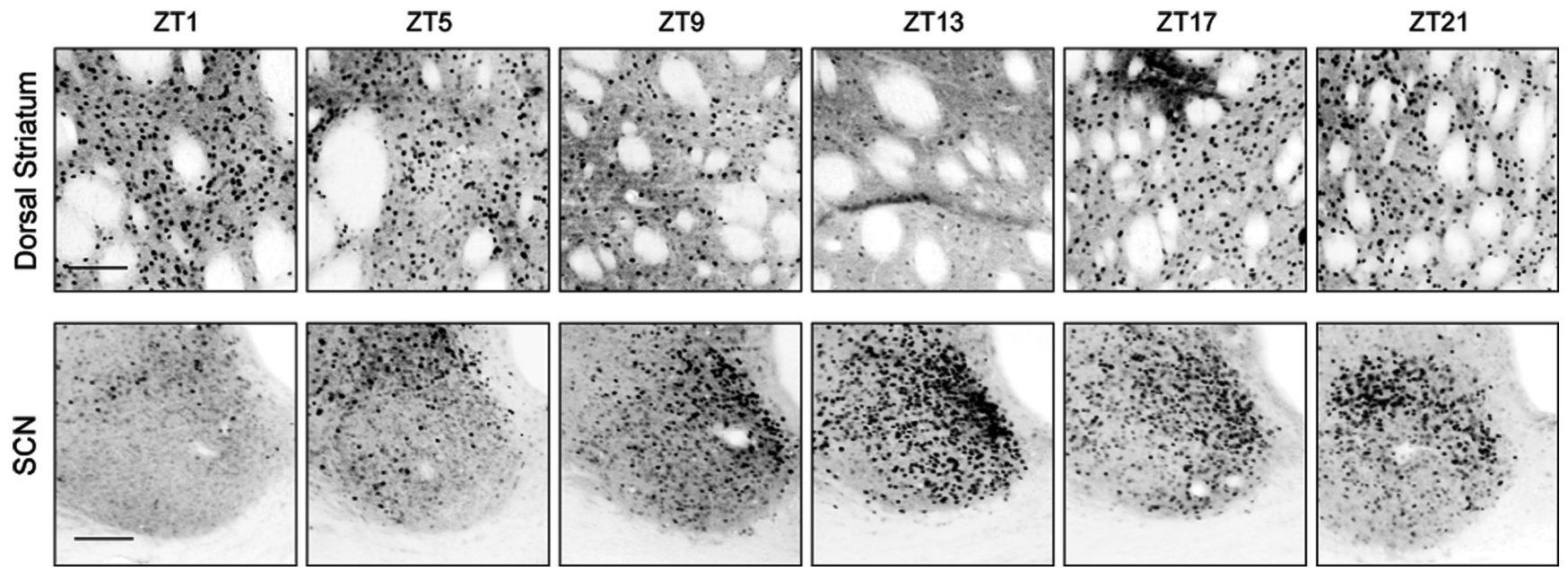

Figure 1. PER2 immunoreactivity fluctuates in a $24 \mathrm{~h}$ rhythm in the dorsal striatum (top row) and the SCN (bottom row). Rats housed in a $12 \mathrm{~h} \mathrm{LD}$ cycle were killed at $4 \mathrm{~h}$ intervals over $24 \mathrm{~h}$ beginning $1 \mathrm{~h}$ after lights were turned on (ZT1). In the dorsal striatum, PER2-IR nuclei are most abundant around ZT1, whereas in the SCN, PER2-IR nuclei are most abundant around ZT13. Scale bar, $100 \mu \mathrm{m}$.

\section{a Dorsal striatum}

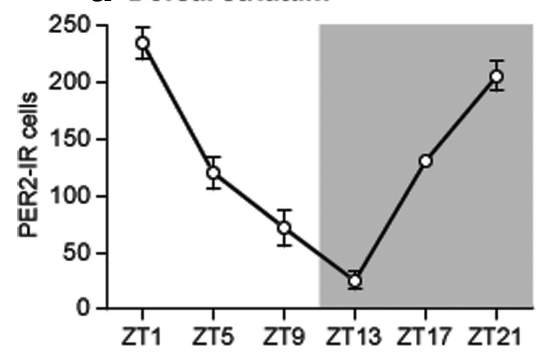

b SCN

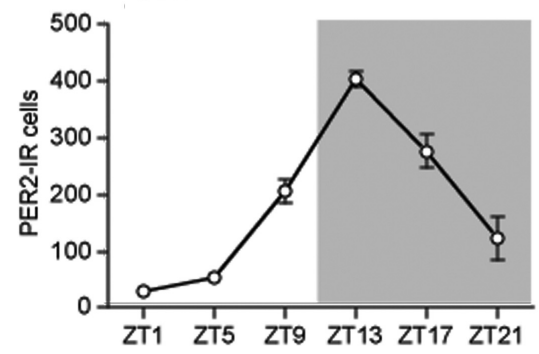

C Extracellular DA

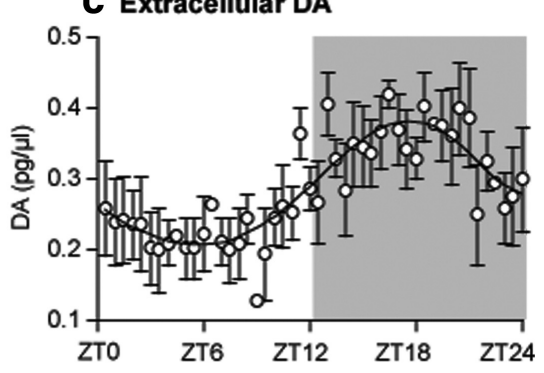

d wheel running

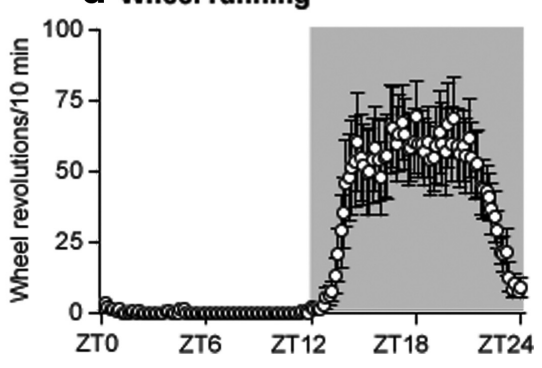

Figure 2. In rats housed in a $12 \mathrm{~h} \mathrm{LD}$ cycle, the $24 \mathrm{~h}$ rhythm of PER2 immunoreactivity in the dorsal striatum (a) is opposite in phase to the rhythm of PER2 expression in the SCN $(\boldsymbol{b})$. The daily fluctuations in extracellular striatal DA levels $(\boldsymbol{c})$ and wheelrunning activity ( $\boldsymbol{d}$ ) peak at night, preceding the peak of PER2 in the striatum. In each panel, the gray block indicates the time of day when lights were off (between ZT12-ZT24). $\boldsymbol{a}$, In the dorsal striatum, PER2 expression is greatest at ZT1, near the beginning of the light phase, and is lowest during the dark phase (expressed as mean number of PER2-IR nuclei \pm SEM at each ZT; $n=4$ per ZT). $\boldsymbol{b}$, In the SCN, PER2 expression is greatest at ZT13, near the beginning of the dark phase, and is lowest during the light phase. $\boldsymbol{c}$, In vivo microdialysis sampling in the dorsal striatum shows that extracellular DA levels are lowest during the middle of the light phase and highest in the middle of the dark phase (expressed as mean picograms of DA/microliter of dialysate $\pm S E M$, samples taken every $30 \mathrm{~min} ; n=3$ ). $\boldsymbol{d}$, Wheel-running activity is also greatest during the dark phase and is virtually absent during the light phase (expressed as mean wheel revolutions/10 $\mathrm{min}$ bin over $24 \mathrm{~h} \pm \mathrm{SEM} ; n=24$ ).

unilateral injections of 6-OHDA in the right or left MFB to destroy dopaminergic inputs to the dorsal striatum and examined PER2 expression in both the lesioned and intact hemispheres. Immunohistochemical staining of DAT expression confirmed that the unilateral 6-OHDA injection caused a dramatic loss of dopaminergic fibers in the dorsal striatum ipsilateral to the toxin injection (Fig. 3). Figure 4 shows examples of PER2 expression and the mean number of PER2-IR nuclei in the dorsal striatum (Fig. $4 a, b$ ) and SCN (Fig. 4c,d), on the intact side and lesioned side in rats killed $14 \mathrm{~d}$ after 6-OHDA injection. In the dorsal striatum (Fig. 4b), the 6-OHDA injection severely blunted the rhythm of PER2 expression in the lesioned hemisphere, but did not affect the normal PER2 rhythm on the intact side (main effect of ZT, $F_{(3,17)}=32.36, p<$ 0.01 ; main effect of lesion, $F_{(1,17)}=80.33$, $p<0.01$; ZT by lesion interaction, $F_{(3,17)}=$ 92.23, $p<0.01)$. Specifically, PER2 expression in the 6-OHDA-lesioned striatum was significantly reduced at ZT1 $\left(t_{(5)}=\right.$ 13.60; $p<0.01)$ and ZT19 $\left(t_{(3)}=7.41\right.$; $p<0.01$ ). In the SCN (Fig. $4 d$ ), the 6-OHDA injection had no effect on the normal rhythm of PER2-IR in either the lesioned or the intact hemispheres (main effect of ZT, $F_{(3,18)}=44.28, p<0.01$; ZT13 significantly greater than ZT1 and ZT7, $p<0.05$, post hoc comparisons with Bonferroni correction; main effect of lesion, $F_{(1,18)}=3.70$, n.s.; ZT by lesion interaction, $F_{(3,18)}=0.88$, n.s.).

Previous reports have indicated that 6-OHDA-lesioned dopaminergic systems can undergo some degree of recovery over time, particularly when rats engage in exercise after the lesion (Tillerson et al., 2003; Moroz et al., 2004; Anstrom et al., 2007). To determine whether any recovery of PER2 expression would develop in the lesioned striatum with time after the 6-OHDA injection, a group of rats was killed $28 \mathrm{~d}$ after receiving a unilateral 6-OHDA injection into the MFB. In the dorsal striatum, PER2 expression at ZT1 was significantly reduced in the lesioned hemisphere compared with the intact hemisphere $28 \mathrm{~d}$ after the 6-OHDA injection (data not shown) (main effect of ZT, $F_{(1,3)}=56.85, p<0.01$; main effect of lesion, $F_{(1,3)}=171.94, p<0.01$; ZT by lesion interaction, $F_{(1,3)}=$ $194.00, p<0.01$; ZT1 paired-samples $t$ test, $t_{(1)}=18.42, p=0.04$; ZT13 paired-samples $t$ test, $t_{(2)}=-0.63$, n.s.). In the SCN, there 
was no effect of the lesion on the daily variation of PER2 expression (data not shown) (main effect of ZT, $F_{(1,3)}=273.84, p<0.01$; main effect of lesion, $F_{(1,3)}=0.62$, n.s.; ZT by lesion interaction, $F_{(1,3)}=1.08$, n.s.). This finding indicates that the blunting of peak PER2 expression in the dorsal striatum after a unilateral 6-OHDA lesion does not recover with time, even when rats have access to running wheels in the intervening period.

To confirm that the effect of the 6-OHDA lesion on the PER2 rhythm in the dorsal striatum was attributable to the elimination of DA inputs to this region and not merely to a mechanical lesion of MFB fibers, two additional groups of rats received a unilateral injection of either 6-OHDA or vehicle $(0.5 \%$ ascorbic acid in saline) into the MFB and were killed $14 \mathrm{~d}$ later at either ZT1 or ZT13. As shown in Figure $5 a$, in 6-OHDA-treated rats, PER2 expression in the dorsal striatum was significantly reduced at ZT1 on the lesioned side, whereas there was no effect on PER2 in vehicle-injected rats in either hemisphere (Fig. $5 d$ ), indicating that the changes in PER2 in the striatum can be unambiguously attributed to the elimination of the DA innervation. As expected, PER2 expression in the SCN was not affected in either treatment group (Fig. 5b,e).

An additional finding from the 6-OHDA lesion group in this latter experiment is that although wheel-running activity across the $24 \mathrm{~h}$ period remains rhythmic, the amount of nighttime activity in the 6-OHDA-lesioned rats is significantly reduced (Fig. $5 c$ ). This might raise the possibility that the unilateral change in PER2 expression seen after unilateral DA depletion could in some way be related to changes in levels of nighttime activity. Contrary to this idea, however, a similar reduction in activity levels was observed in vehicle-treated rats (Fig. 5f). Thus, changes in PER2 expression appear to be related specifically to DA and not to a reduction in locomotor activity.

\section{Per 2 transcription in the dorsal striatum after unilateral 6-OHDA lesion}

To examine whether the reduction in PER2 expression in the 6-OHDA-lesioned dorsal striatum is associated with changes in transcription of the Per2 gene, we performed real-time PCR (RTPCR) on samples of striatal tissue from rats killed at either ZT7 or ZT19 2 weeks after a unilateral injection of 6-OHDA or vehicle into the MFB. These data are shown in Figure 6. In the intact hemisphere, Per2 transcription levels are greater at ZT19 than ZT7. Notably, levels of Per2 transcription at ZT19 were signifihemispheres, $p<0.05$.
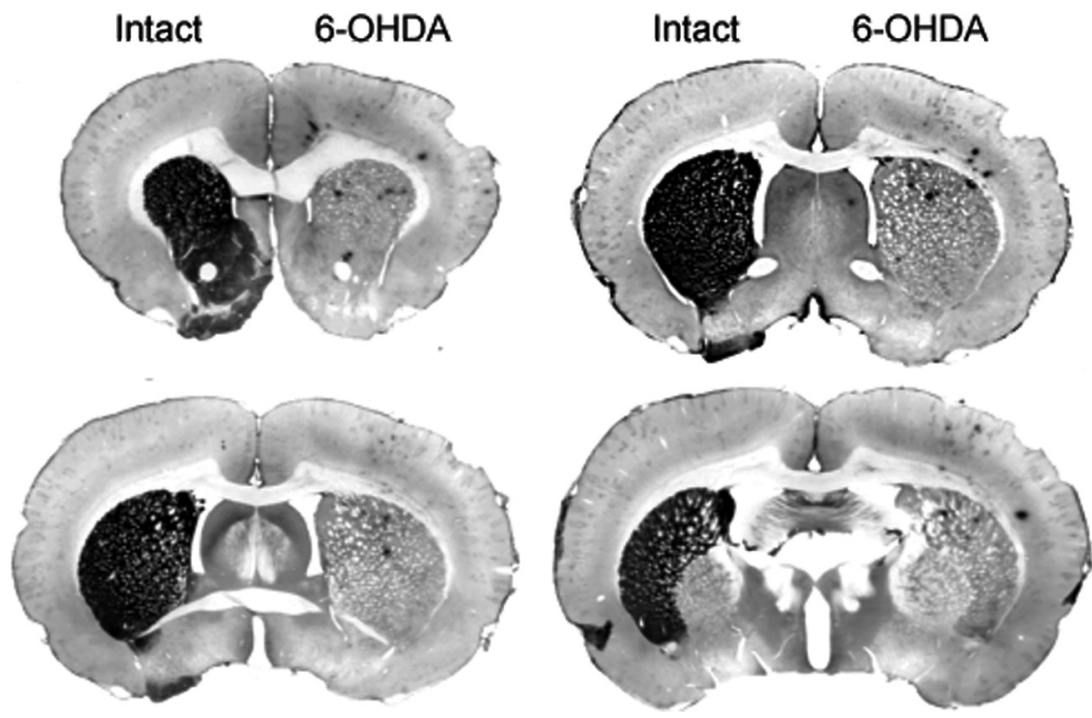

Figure 3. Photomicrographs showing the effect of unilateral injection of 6-OHDA into the MFB on DAT immunoreactivity (shown in black) in the dorsal striatum ipsilateral to the injection. Lack of stain on the 6-OHDA side indicates a loss of DA input to the striatum in the lesioned hemisphere. Rats were killed $14 \mathrm{~d}$ after receiving a unilateral 6-0HDA injection (8 $\mu \mathrm{g}$ ). a
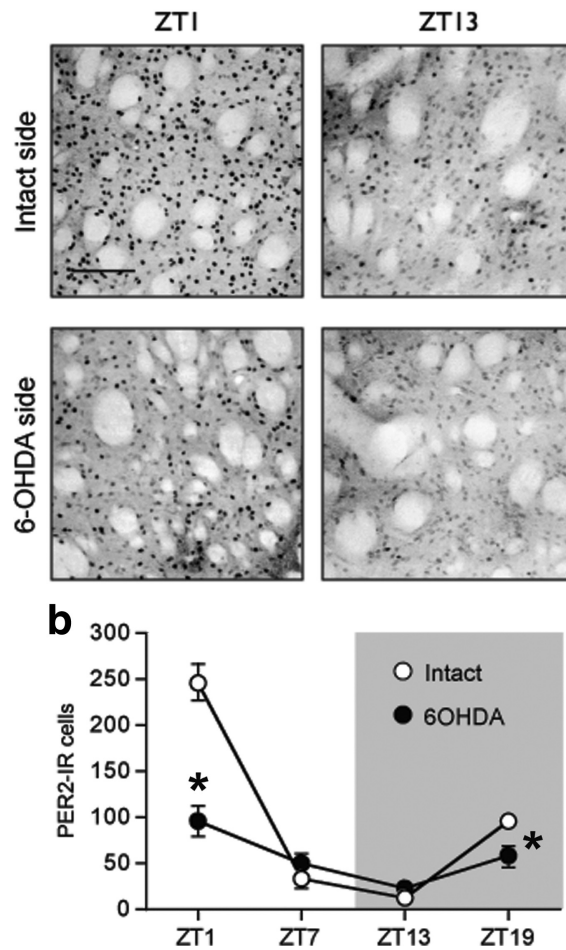

C
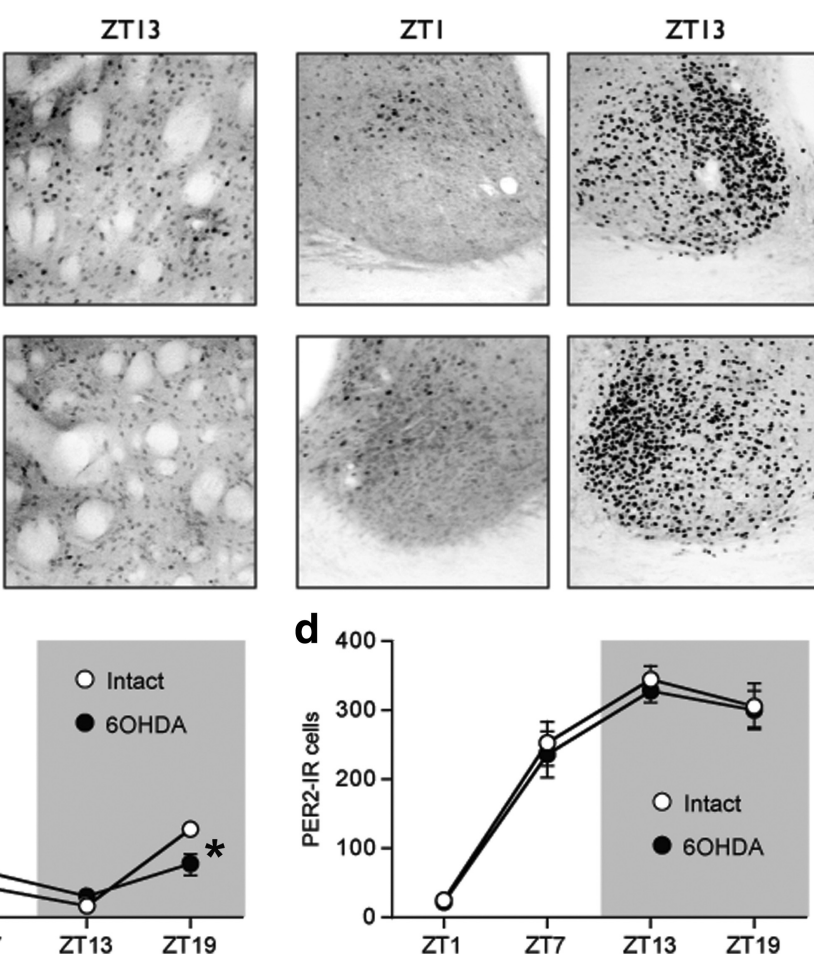

ZTI3

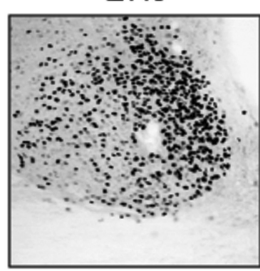

Figure 4. A unilateral 6-OHDA injection into the MFB selectively reduces the normal morning peak of PER2 expression in the dorsal striatum ipsilateral to the lesion but does not affect the PER2 rhythm in the SCN. $\boldsymbol{a}, \boldsymbol{c}$, Photomicrographs showing PER2 expression in the intact and 6-OHDA-treated hemispheres in the dorsal striatum (a) and SCN (c) in rats killed at ZT1 or ZT13. $\boldsymbol{b}, \boldsymbol{d}$, Means \pm SEM of PER2-IR nuclei on the intact and lesioned hemispheres in the dorsal striatum $(\boldsymbol{b})$ and SCN (d) in rats killed at ZT1, 7, 13, and 19, 2 weeks after 6-OHDA treatment $(n=5-6$ per ZT). *Significant difference between the intact and lesioned

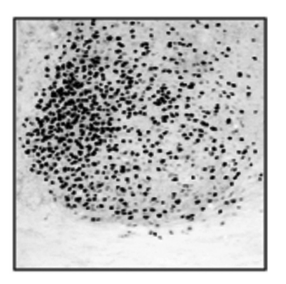

cantly reduced in the dorsal striatum ipsilateral to a 6-OHDA injection (Fig. $6 a$ ) (main effect of ZT, $F_{(1,6)}=6.70, p<0.05$; main effect of 6-OHDA lesion, $F_{(1,6)}=3.21$, n.s.; ZT by lesion interaction, $\left.F_{(1,6)}=5.55, p=0.05\right)$ but were unaffected by a vehicle injection (Fig. 6b) (main effect of ZT, $F_{(1,6)}=6.40, p<0.05$; main effect of sham lesion, $F_{(1,6)}=0.09$, n.s.; ZT by sham lesion inter- 

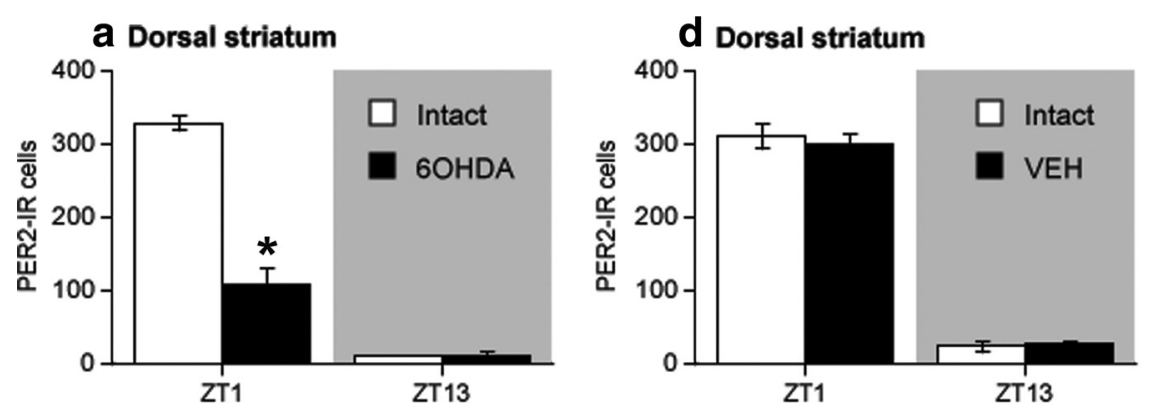

b SCN
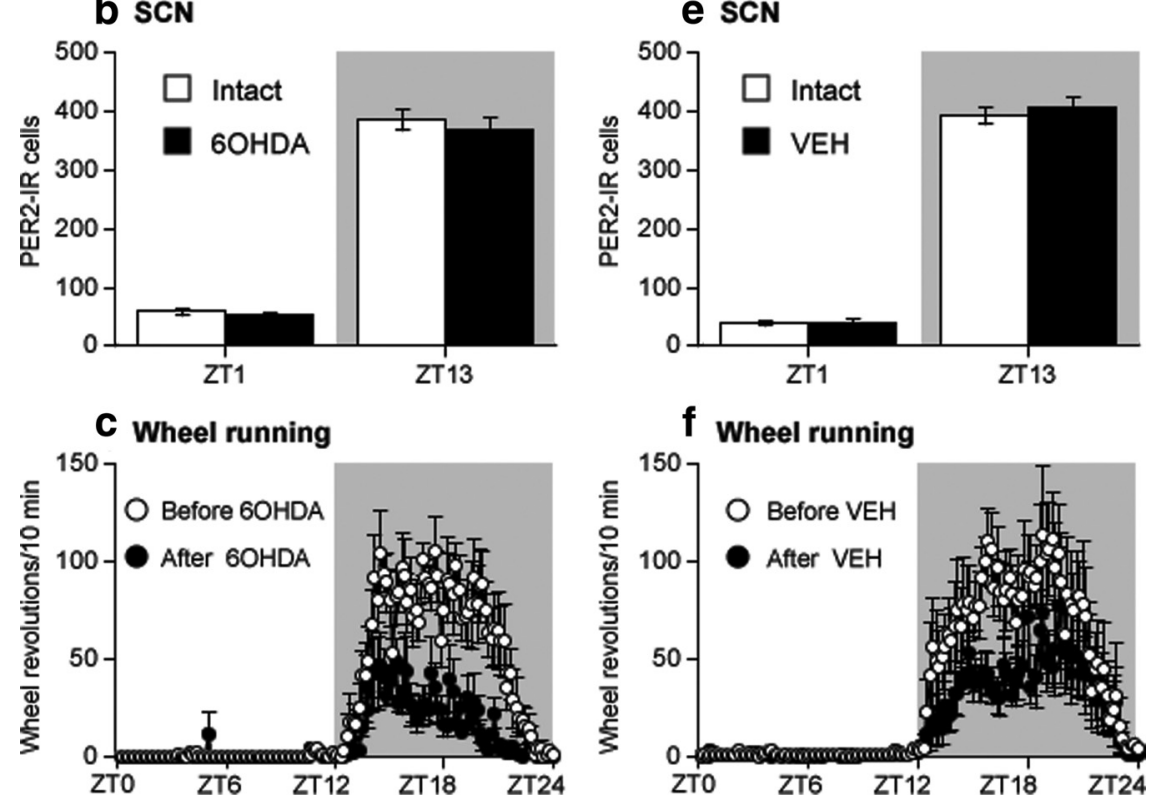

Figure 5. Intra-MFB injection of 6-OHDA blunts the daytime increase in PER2 expression in the dorsal striatum (a), whereas a vehicle (VEH) injection into the MFB has no effect ( $\boldsymbol{d}$ ) (expressed as mean PER2-IR nuclei at each ZT $\pm S E M ; n=3$ per ZT). In the SCN, neither a unilateral 6-OHDA injection $(\boldsymbol{b})$ nor a vehicle injection $(\boldsymbol{e})$ into the MFB disrupts the daily fluctuation in PER2 expression. In contrast to the selective effect of 6-OHDA on PER2 in the dorsal striatum, nighttime wheel-running activity (expressed as mean wheel revolutions/10 min bin over $24 \mathrm{~h} \pm$ SEM) is decreased after a unilateral intra-MFB injection of either $6-0 \mathrm{HDA}(\boldsymbol{c})$ or vehicle $(\boldsymbol{f})$. ${ }^{*}$ Significant difference between the intact and lesioned hemispheres, $p<0.05$.

action, $F_{(1,6)}=0.15$, n.s.). These findings indicate that dopaminergic input to the dorsal striatum regulates the transcription of Per2, and suggest that the reduction in PER2 protein in the dorsal striatum after a 6-OHDA lesion is at least partly attributable to a reduction in gene expression.

\section{PER1 expression after unilateral 6-OHDA lesion}

In view of evidence that DA receptor agonists modulate the expression of the clock gene Perl in the dorsal striatum (Nikaido et al., 2001), we also examined the effect of a unilateral 6-OHDA injection into the MFB on the rhythm of expression of the PER1 protein in the dorsal striatum and SCN using alternate brain sections from rats in our first 6-OHDA lesion experiment. These data are shown in Figure 7. In the dorsal striatum (Fig. 7a), the normal rhythm of PER1 expression approximates the rhythm of PER2 in this region and peaks near ZT1. After the 6-OHDA lesion, the amplitude of this rhythm in the lesioned hemisphere was significantly blunted compared with the intact hemisphere (main effect of ZT, $F_{(3,12)}=10.53, p<0.01$; main effect of lesion, $F_{(1,12)}=21.60$, n.s.; ZT by lesion, $\left.F_{(3,12)}=11.24, p<0.05\right)$ and PER1 was significantly reduced in the lesioned hemisphere at ZT1 $(p<0.05)$ and ZT19 $(p<0.05)$. In the SCN, the normal rhythm of PER1 expression is similar to the rhythm of PER2 and peaks near ZT13. As shown in Figure 7b, the 6-OHDA lesion did not affect PER1 in the SCN (main effect of ZT, $F_{(3,12)}=$ 11.37, $p<0.01$; main effect of lesion, $F_{(1,12)}=1.09$, n.s.; ZT by lesion interaction, $F_{(3,12)}=0.09$, n.s.).

\section{PER2 expression after inhibition of} tyrosine hydroxylase

The results of our 6-OHDA experiments indicate that a unilateral lesion of dopaminergic projections and subsequent depletion of $\mathrm{DA}$ in the dorsal striatum significantly blunts the normal rhythm of PER2 expression in this region without affecting the rhythm in the SCN. To determine whether pharmacological depletion of DA without destruction of DA cells would produce the same result, we gave three injections of the tyrosine hydroxylase inhibitor, AMPT, over $8 \mathrm{~h}$. The first injection was given at ZT0 (AMPT, $300 \mathrm{mg} / \mathrm{kg}$, or vehicle, $1 \mathrm{ml} / \mathrm{kg}$ ), the second injection at ZT4 (AMPT, $200 \mathrm{mg} / \mathrm{kg}$, or vehicle), and the third injection at ZT8 (AMPT, $200 \mathrm{mg} / \mathrm{kg}$, or vehicle). Rats were then perfused for immunohistochemistry or decapitated for HPLC quantification of DA at ZT13, $5 \mathrm{~h}$ after the last injection, or at $\mathrm{ZT} 1,17 \mathrm{~h}$ after the last injection.

Analysis of striatal tissue punches from both hemispheres using HPLC revealed a 95\% reduction in DA content in AMPTtreated rats killed at ZT13 and an $88 \%$ reduction in DA content in AMPT-treated rats killed at ZT1 (Fig. 8a), indicating a profound depletion of DA in the dorsal striatum as a result of this treatment (ZT1 independent-samples $t$ test, $t_{(2)}=13.05$, $p<0.01$; ZT13 independent-samples $t$ test, $\left.t_{(2)}=29.02, p<0.01\right)$. Figure $8, b$ and $c$, shows the daily fluctuation in PER2 expression in the dorsal striatum and SCN of rats injected with AMPT or vehicle. In the dorsal striatum (Fig. 8b), AMPT significantly reduced PER2 expression at ZT1 (main effect of ZT, $F_{(1,11)}=31.45, p<0.01$; main effect of treatment, $F_{(1,11)}=10.28, p<0.01$; ZT by treatment interaction, $F_{(1,11)}=25.56, p<0.01$; independent-samples $t$ test at ZT1, $\left.t_{(6)}=4.66, p<0.01\right)$ and slightly increased it at ZT13 compared with the vehicle group (independent-samples $t$ test, $\left.t_{(5)}=-3.22, p<0.05\right)$. AMPT treatment had no effect on PER2 expression in the SCN (Fig. $8 c$ ) (main effect of ZT, $F_{(1,12)}=$ $1208.25, p<0.01$; main effect of treatment, $F_{(1,12)}=0.17$, n.s.; ZT by treatment interaction, $F_{(1,12)}=1.66$, n.s.). These findings corroborate the results of our unilateral 6-OHDA lesion experiments and indicate that depletion of normal DA levels in the dorsal striatum by lesioning or pharmacological means blunts the normal daily peak in PER2 expression in this region. Interestingly, the magnitude of the AMPT effect on striatal PER2 appears larger than the effect of a 6-OHDA lesion. Because inhibition of tyrosine hydroxylase prevents the synthesis of noradrenaline (NA) as well as dopamine, it is possible that the additional decrease in PER2 after AMPT reflects a role for NA in the regulation of PER2 expression in the dorsal striatum. 
a

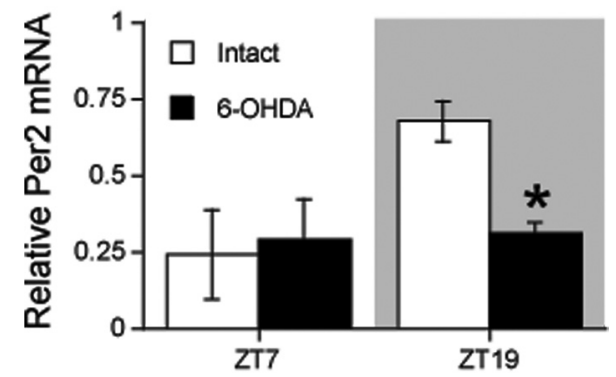

b

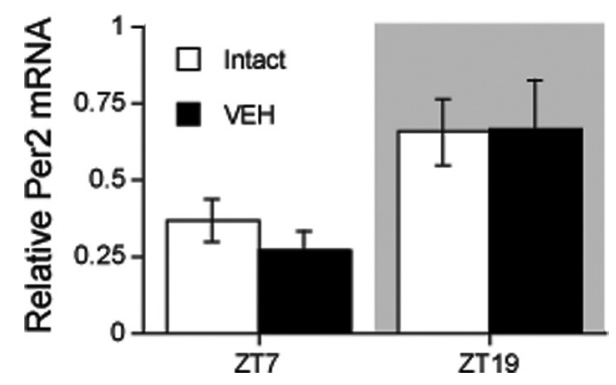

Figure 6. A unilateral 6-OHDA lesion selectively reduces Per2 transcription in the dorsal striatum ipsilateral to the lesion. Means \pm SEM of Per2 mRNA levels in the intact and 6-OHDAlesioned hemisphere in rats killed at ZT7 or 19,2 weeks after an injection of either 6-0HDA toxin $(\boldsymbol{a})$ or vehicle (VEH) $(\boldsymbol{b})$ into the MFB ( $n=3$ per ZT). Relative mRNA level represents transcript levels as normalized values relative to the highest level of Per 2 transcription observed in all samples. * Significant difference between the intact and lesioned hemispheres, $p<0.05$.
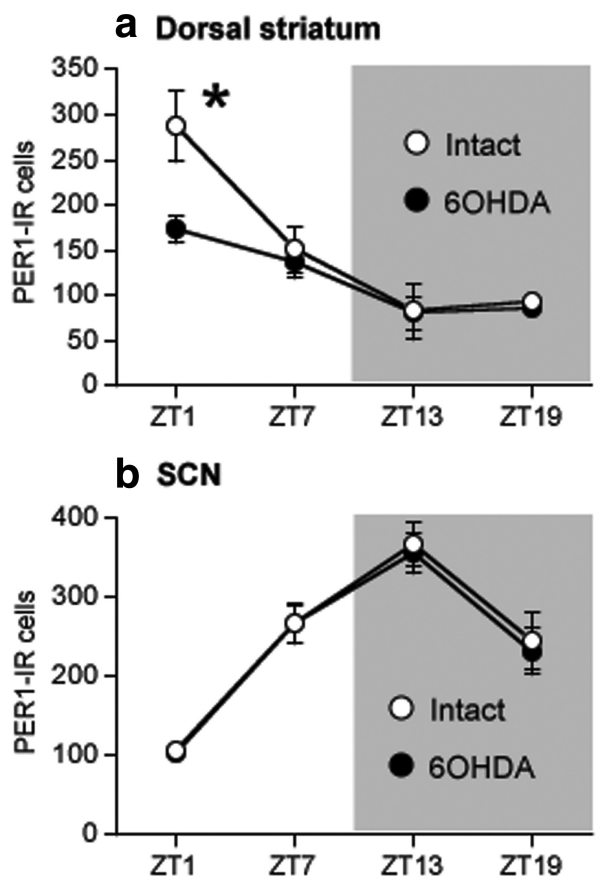

Figure 7. Aunilateral6-OHDA lesion selectively reduces the normal morning peak ofPER1 expression in the dorsal striatum ipsilateral to the lesion but does not affect the PER1 rhythm in the SCN. Means \pm SEM of PER1-IR nuclei in the intact and lesioned hemispheres in the dorsal striatum $(\boldsymbol{a})$ and SCN $(\boldsymbol{b})$ in rats killed at ZT1, 7, 13, and 19, 2 weeks after 6-0HDA treatment ( $n=5-6$ per ZT). *Significant difference between the intact and lesioned hemispheres, $p<0.05$.

PER2 expression in primary motor cortex and hippocampus after 6-OHDA lesion and inhibition of tyrosine hydroxylase To confirm that the effect of the 6-OHDA lesion on PER2 in the dorsal striatum was attributable to a loss of DA innervation and a DA-Dorsal striatum

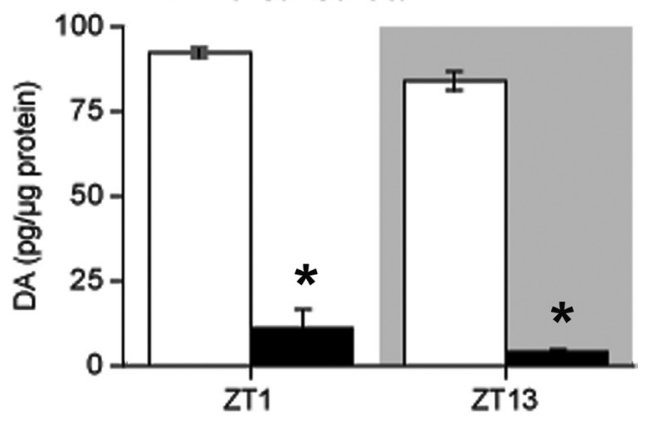

b PER2-Dorsal striatum

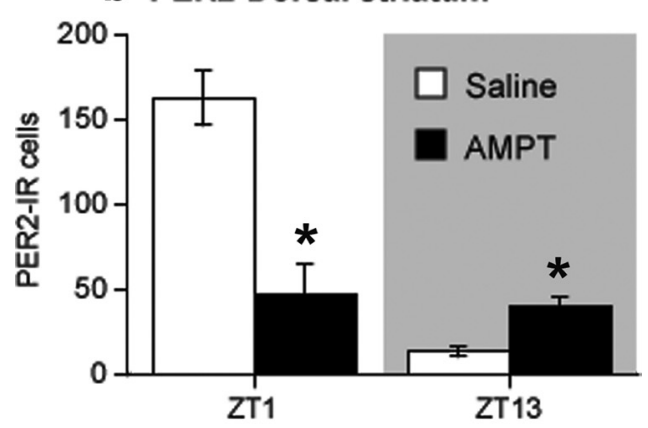

C PER2-SCN

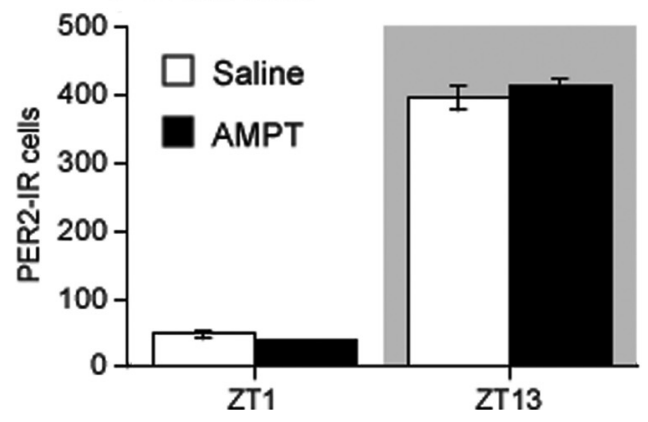

Figure 8. Inhibition of tyrosine hydroxylase activity suppresses DA levels and daytime PER2 expression in the dorsal striatum. Rats were given three injections of AMPT or saline over $8 \mathrm{~h}$ and then killed at either ZT13 ( $5 \mathrm{~h}$ after the last injection) or ZT1 (17 $\mathrm{h}$ after the last injection). $\boldsymbol{a}, \mathrm{DA}$ content in the dorsal striatum (expressed as picograms of DA/microgram of protein) in AMPTinjected rats (black bars) was significantly decreased at both ZT1 and ZT13 compared with saline-injected rats (white bars; $n=2$ per treatment group per ZT; * $p<0.05$ ). $\boldsymbol{b}$, In the dorsal striatum, AMPT treatment decreased daytime PER2 expression at ZT1 and increased PER2 at ZT13 compared with saline controls (expressed as mean PER2-IR nuclei \pm SEM at each ZT; $n=$ 4 per treatment group per ZT; $\left.{ }^{*} p<0.05\right)$. c, In the SCN, AMPT treatment had no effect on PER2 expression at either time point.

not to a nonspecific lesion of catecholamines fibers in general, we examined the effects of a 6-OHDA lesion and AMPT treatment on PER2 expression in two other regions innervated by NA fibers, namely primary motor cortex (M1) and the dentate gyrus of the hippocampus (DG) (Swanson and Hartman, 1975; Fallon et al., 1978; Asan, 1998). In both M1 and DG, the normal daily fluctuation in PER2 expression peaks at ZT1 and falls at ZT13, consistent with the PER2 phase in the dorsal striatum. As shown in Figure 9, a unilateral 6-OHDA lesion had no effect on PER2 expression in M1 (Fig. 9a) or DG (Fig. 9c) in either hemisphere. In contrast, systemic AMPT treatment dramatically decreased PER2 expression at ZT1 in both M1 (Fig. 9b) and DG (Fig. 9d). Together, these results indicate that catecholamines regulate the daily fluctuation in PER2 expression in M1 and DG. The dissociation between the effects of 6-OHDA and AMPT, how- 

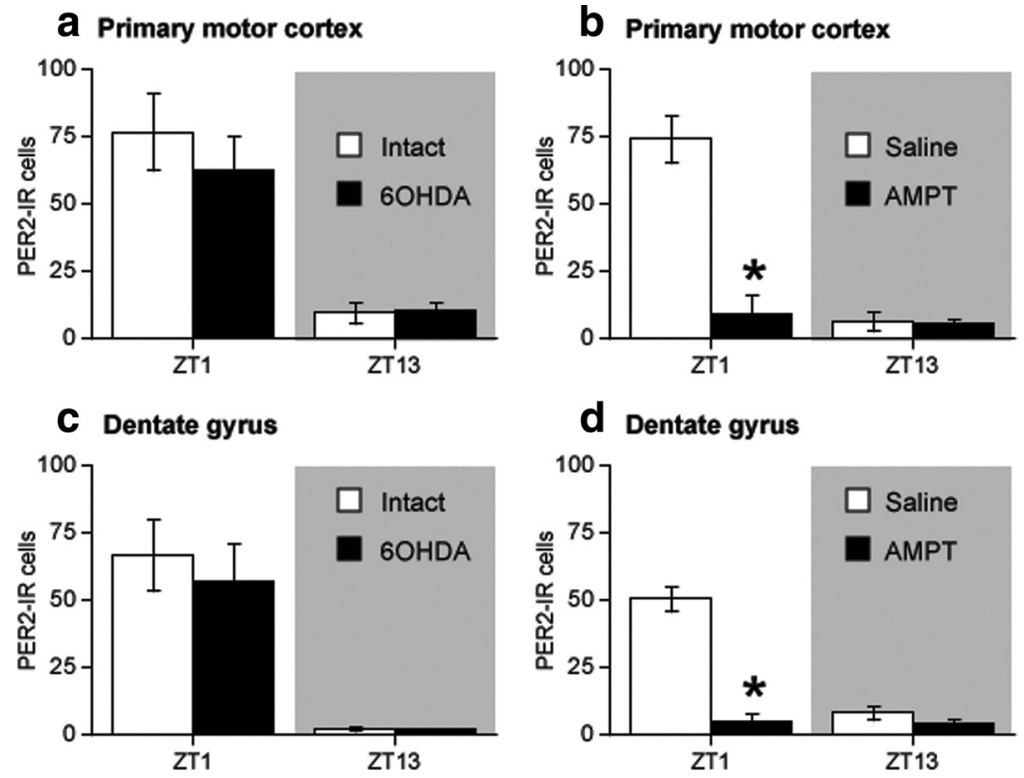

Figure 9. A unilateral 6-OHDA infusion into the MFB has no effect on PER2 in primary motor cortex (M1) or in the dentate gyrus (DG), whereas treatment with AMPT strongly suppresses the normal peak of PER2 expression in each of these regions. Mean PER2-IR nuclei \pm SEM in the intact and 6-OHDA-lesioned hemispheres of M1 (a) and DG (c) after a unilateral 6-OHDA lesion ( $n=$ 5 per ZT). Mean PER2-IR nuclei \pm SEM in primary motor cortex $(\boldsymbol{b})$ and DG $(\boldsymbol{d})$ after AMPT treatment $(n=4$ per treatment group per ZT; $\left.{ }^{*} p<0.05\right)$

ever, suggests that the catecholaminergic regulation of PER2 in these regions is primarily attributable to NA. Importantly, the lack of effect of the 6-OHDA lesion on PER2 in these regions indicates that the lesion did not damage NA fibers in addition to DA fibers.

\section{PER2 expression during chronic treatment with DA receptor antagonists}

Having found that a depletion of DA in the dorsal striatum disrupts the normal rhythm of PER2 expression in this region, we investigated whether blocking either $\mathrm{D}_{1}$ or $\mathrm{D}_{2} \mathrm{DA}$ receptors using chronic, $24 \mathrm{~h}$ infusion of DA receptor antagonists would affect the normal rhythm of PER2 expression in the dorsal striatum and SCN. After a $10 \mathrm{~d}$ entrainment period, naive rats underwent surgery to receive osmotic minipumps containing the $\mathrm{D}_{1} \mathrm{DA}$ receptor antagonist, $\mathrm{SCH} 23390\left(0.5 \mathrm{mg} \cdot \mathrm{kg}^{-1} \cdot 24 \mathrm{~h}^{-1}\right)$, or the $\mathrm{D}_{2}$ DA receptor antagonist, raclopride $\left(2 \mathrm{mg} \cdot \mathrm{kg}^{-1} \cdot 24 \mathrm{~h}^{-1}\right)$, or underwent sham surgery (no pump inserted). Rats remained in their home cages for $5 \mathrm{~d}$ after pump insertion and were then perfused at either ZT1 or ZT13. The doses of SCH 23390 and raclopride were chosen on the basis of previous studies indicating dose ranges that were effective in occupying $\sim 80 \%$ of striatal $\mathrm{D}_{1}$ or $\mathrm{D}_{2}$ DA receptors and that did not impede motor function (Creese and Chen, 1985; Neisewander et al., 1998; Wadenberg et al., 2001; Kapur et al., 2003). The duration of drug treatment was limited to $5 \mathrm{~d}$ in this experiment because of evidence indicating that longer delivery of DA antagonists is less effective than shorter-term treatment in blocking DA receptors because of increasing sensitivity of DA receptors over time (Samaha et al., 2008).

The results of this experiment are shown in Figure 10. In the dorsal striatum (Fig. 10a), PER2 expression was unaffected by $5 \mathrm{~d}$ of chronic treatment with the $\mathrm{D}_{1} \mathrm{DA}$ antagonist, $\mathrm{SCH}$ 23390, but was significantly reduced at ZT1 by chronic infusion of the $\mathrm{D}_{2}$ DA antagonist, raclopride (ZT by treatment interaction, $F_{(2,18)}=8.24, p<0.01$; one-way ANOVA at ZT1, $F_{(2,9)}=5.53, p<0.05$, raclopride group less than vehicle and
SCH 23390 groups, $p<0.05$, post hoc comparison with Bonferroni correction). No differences in PER2 expression between groups were found at ZT13 in the dorsal striatum (one-way ANOVA at ZT13, $F_{(2,9)}=2.93$, n.s.). In the SCN (Fig. 10b), neither SCH 23390 nor raclopride changed the normal daily variation in PER2 (main effect of ZT, $F_{(1,18)}=$ 727.79, $p<0.01$; main effect of treatment, $F_{(2,18)}=1.07$, n.s.; ZT by treatment interaction, $F_{(2,18)}=0.69$, n.s.). These results suggest that the normal PER2 rhythm in the dorsal striatum depends on the availability of $\mathrm{D}_{2}$, but not $\mathrm{D}_{1}$ DA receptors.

\section{Effect of $D_{1}$ or $D_{2 / 3}$ DA receptor agonist injections on PER2 expression and wheel running in 6-OHDA-lesioned rats}

Previous research indicates that changes in the expression of peptides and receptors in striatal medium spiny neurons that develop after a unilateral 6-OHDA lesion can be reversed with intermittent or chronic DA receptor agonist treatment (Gerfen et al., 1990). To investigate whether such treatments could also restore the normal rhythm of PER2 expression in the 6-OHDA-lesioned dorsal striatum, we gave systemic injections of the $\mathrm{D}_{1}$ DA agonist, SKF $81297(1 \mathrm{mg} / \mathrm{kg})$, the $\mathrm{D}_{2 / 3}$ DA agonist, quinpirole $(0.5 \mathrm{mg} / \mathrm{kg})$, or vehicle $(1 \mathrm{ml} / \mathrm{kg})$ at ZT1 for $10 \mathrm{~d}$, beginning $15 \mathrm{~d}$ after surgery. Drug doses were in the range shown previously to enhance expression of immediate-early genes, striatal peptides, and electrophysiological responses of striatal neurons in 6OHDA-lesioned rats (Gerfen et al., 1990, 1995; Hu et al., 1992; Zhang et al., 2007; Ballion et al., 2009). We chose to give the daily agonist injection at ZT1, a time at which extracellular DA levels in the striatum are normally low, to determine whether exogenous stimulation of DA receptors would not only restore PER2 expression in the lesioned striatum, but also establish a new rhythm of PER2 expression whose phase was determined by the time of the agonist injection. Rats were then killed on the day after the last injection at either ZT1 or ZT13.

The results of this experiment are shown in Figure 11. As shown previously, a unilateral 6-OHDA lesion blunted the daily variation of PER2 expression in the dorsal striatum on the lesioned side by strongly reducing the normal peak seen at ZT1 (ZT by lesion interaction, $F_{(1,27)}=85.64, p<0.01$ ) (vehicle-treated rats) (Fig. 11a). Daily systemic injection of quinpirole at ZT1 restored and reversed the daily fluctuation of PER2 expression on the lesioned side. Specifically, quinpirole had no effect on PER2 expression at ZT1 (Fig. 11b) (oneway ANOVA at ZT1, $F_{(2,14)}=0.16$, n.s.) but dramatically increased expression of PER2 at ZT13, a time when the normal rhythm of PER2 expression in the striatum would otherwise be at its trough (one-way ANOVA at ZT13, $F_{(2,13)}=64.02, p<$ $0.01)$. It can also be seen in Figure $11 b$ that quinpirole injections had no effect on the normal daily variation in PER2 expression in the intact dorsal striatum (main effect of ZT, $F_{(1,27)}=174.99, p<0.01 ;$ main effect of treatment, $F_{(2,27)}=$ 0.04 , n.s.; ZT by treatment interaction, $F_{(2,27)}=2.00$, n.s.). Daily injection of SKF 81297 at ZT1 (Fig. 11c) had no effect on 
a Dorsal striatum

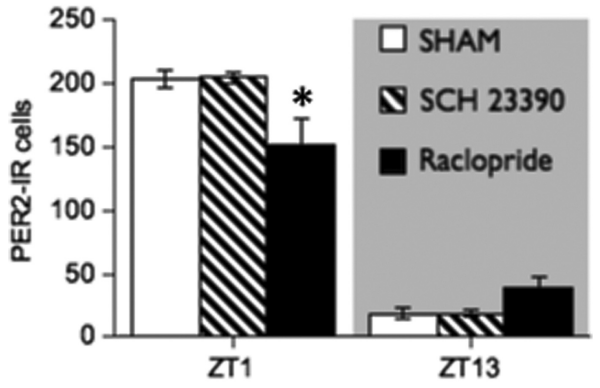

b SCN

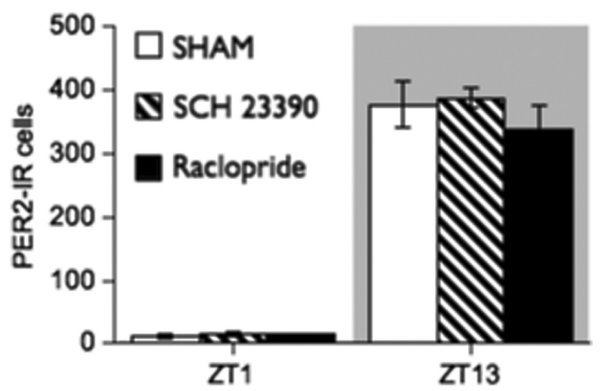

Figure 10. $\boldsymbol{a}$, Continuous infusion of the $D_{2} D A$ receptor antagonist, raclopride (2 $\mathrm{mg} \cdot \mathrm{kg}^{-1} \cdot 24 \mathrm{~h}^{-1}$ ), for $5 \mathrm{~d}$ via osmotic minipump reduces daytime expression of PER2 in the dorsal striatum, whereas infusion of the $D_{1}$ DA antagonist, SCH $23390\left(0.5 \mathrm{mg} \cdot \mathrm{kg}^{-1} \cdot 24\right.$ $\mathrm{h}^{-1}$ ), has no effect (expressed as mean PER2-IR nuclei \pm SEM at each ZT; $n=4$ per treatment group per ZT). $\boldsymbol{b}$, Neither raclopride nor SCH 23390 infusion affects PER2 in the SCN. * ${ }^{*}$ ignificant difference between raclopride and sham groups, $p<0.05$.

PER2 expression at ZT1 or ZT13 in either the lesioned or intact dorsal striatum.

Consistent with our previous results, unilateral injection of 6-OHDA had no effect on the normal daily variation of PER2 expression in the SCN (Fig. 11d). Furthermore, as shown in Figure $11, e$ and $f$, the daily variation of PER2 expression in the SCN was unaffected by quinpirole or SKF 81297 injection. In contrast, it can be seen from Figure $11 g-i$ that daily injections of the DA agonists had differential effects on wheel-running activity rhythms. Quinpirole strongly suppressed nocturnal activity (Fig. 11h), whereas SKF 81297 increased activity during the day especially around the time of the injections (Fig. 11i).

Having found that a daily injection of quinpirole, but not SKF 81297, at ZT1 establishes a new pattern of PER2 expression in the 6-OHDA-lesioned dorsal striatum, although not in the intact striatum, we asked whether similar treatments with quinpirole or SKF 81297 would have any effect on PER2 expression in the dorsal striatum or SCN of naive, intact rats. No effects of these drug treatments were found in either the dorsal striatum or SCN (data not shown).

Finally, having found that scheduled daily injections of quinpirole restored a rhythm of PER2 expression in the 6-OHDAlesioned dorsal striatum, whereas SKF 81297 injections did not, we asked whether the induction of a new PER2 rhythm in the lesioned dorsal striatum requires a timed, bolus delivery of a DA receptor agonist or only a general level of DA receptor stimulation that is time insensitive. To address this, we prepared rats with unilateral 6-OHDA lesions and inserted osmotic minipumps $15 \mathrm{~d}$ after the 6-OHDA lesion surgery to deliver a constant $24 \mathrm{~h}$ infusion of quinpirole $\left(0.5 \mathrm{mg} \cdot \mathrm{kg}^{-1} \cdot 24 \mathrm{~h}^{-1}\right)$ or SKF 81297 (1 $\left.\mathrm{mg} \cdot \mathrm{kg}^{-1} \cdot 24 \mathrm{~h}^{-1}\right)$. Rats were perfused $10 \mathrm{~d}$ later at either ZT1 or ZT13. As shown in Figure 12a,6-OHDA had the expected effect on PER2 expression in the dorsal striatum at ZT1. Furthermore, it can also be seen that chronic delivery of quinpirole (Fig. 12b) or SKF 81297 (Fig. 12c) at the doses used did not alter the effect of lesions on PER2 expression in the dorsal striatum nor did they alter PER2 expression in the intact hemisphere. No effects were seen in the SCN (Fig. 12d-f). Finally, during the $10 \mathrm{~d}$ period of chronic infusion of quinpirole or SKF 81297, wheel-running activity remained rhythmic in all groups (Fig. 12g-i).

\section{Discussion \\ Daily, timed stimulation of $\mathrm{D}_{2}$ receptors regulates PER2 in the dorsal striatum}

Molecular components of the circadian clock, including Per2, participate in the regulation of striatal dopaminergic activity in rodents (McClung et al., 2005; Roybal et al., 2007; Hampp et al., 2008). In turn, pharmacological stimulation of DA receptors can affect the expression of Per genes in the striatum (Nikaido et al., 2001; Iijima et al., 2002; Uz et al., 2005; Lynch et al., 2008; Imbesi et al., 2009). Here, we examined the role of endogenous DA in the regulation of the expression of the clock protein, PER2, in the dorsal striatum to better characterize the relationship between DA and the circadian oscillations in clock gene expression in this region. We found that treatments that deplete striatal DA strongly blunt the rhythm of PER2 and, furthermore, that daily stimulation of $\mathrm{D}_{2}$, but not $\mathrm{D}_{1} \mathrm{DA}$ receptors, restores and entrains the PER2 rhythm in the DA-depleted striatum. Our findings are consistent with the idea that the rhythm of expression of PER2 in the striatum depends on daily dopaminergic activation of $\mathrm{D}_{2} \mathrm{DA}$ receptors.

The daily peak of extracellular DA in the dorsal striatum preceded that of PER2 by $\sim 6 \mathrm{~h}$. Specifically, extracellular DA levels peak in the middle of the dark (active) phase and fall during the light (inactive) phase of the daily cycle (Paulson and Robinson, 1994; Castañeda et al., 2004), whereas PER2 expression peaks at the beginning of the light phase and reaches its trough near the beginning of the dark phase (Amir et al., 2006). When striatal DA was depleted unilaterally using 6-OHDA, the peak expression of PER2 on the lesioned side was strongly suppressed and the daily rhythm of PER2 in this region was blunted both 2 and 4 weeks after surgery. Furthermore, treatment with AMPT, which blocks the synthesis of DA and other catecholamines acutely, suppressed PER2 expression within $24 \mathrm{~h}$. Thus, normal rhythmic expression of PER2 in the striatum relies on DA availability. We next showed that the rhythm of PER2 in the striatum relies on phasic activation of $\mathrm{D}_{2}$ DA receptors. Daily injections of a $\mathrm{D}_{2}$ DA receptor agonist, given to induce a peak of activation of DA receptors at a time of day when DA levels are normally low, not only restored, but shifted the daily peak of PER2 in the lesioned striatum. Continuous infusion of the $\mathrm{D}_{2}$ DA agonist had no effect, underscoring the role of phasic activation. Neither daily injections nor continuous infusions of a $D_{1}$ DA agonist were effective. Together, these findings point to a link between the daily rise of endogenous $\mathrm{DA}, \mathrm{D}_{2}$ DA receptor activation, and the subsequent peak in PER2 expression in the dorsal striatum.

The requirement of $\mathrm{D}_{2}$ DA receptor activation for the maintenance of the PER2 rhythm in the dorsal striatum is further demonstrated by our finding that chronic infusion of a selective $\mathrm{D}_{2}$, but not $\mathrm{D}_{1}$, DA receptor antagonist attenuates the daily fluctuation in PER2 expression. Given that $D_{2}$ and $D_{1}$ DA receptors in the dorsal striatum are mostly expressed by separate populations of projection neurons, the selective modulation of PER2 through the $\mathrm{D}_{2}$ receptor could provide a clue to the functional significance of rhythmic PER2 expression in this system. 
Dorsal striatum

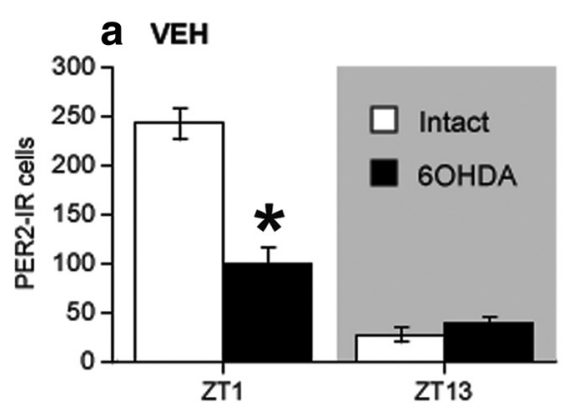

b QUIN

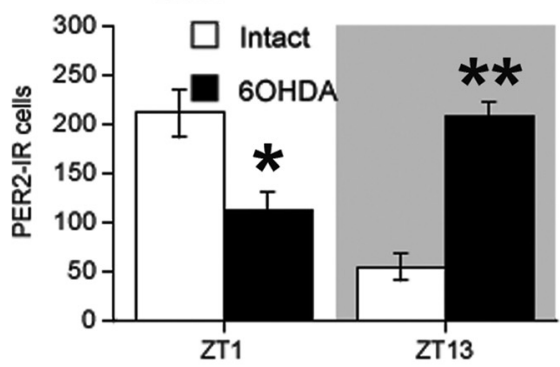

C SKF

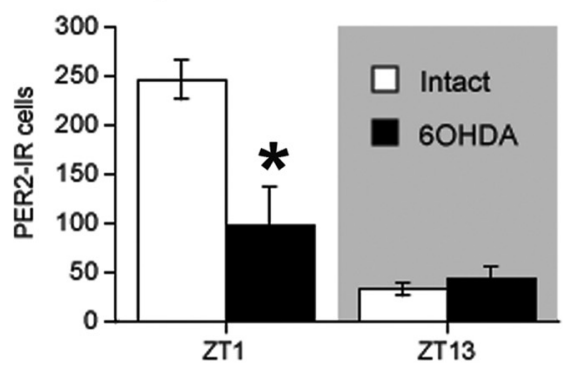

SCN

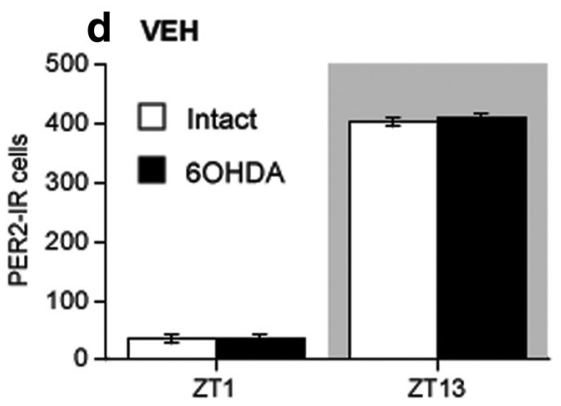

e QUIN

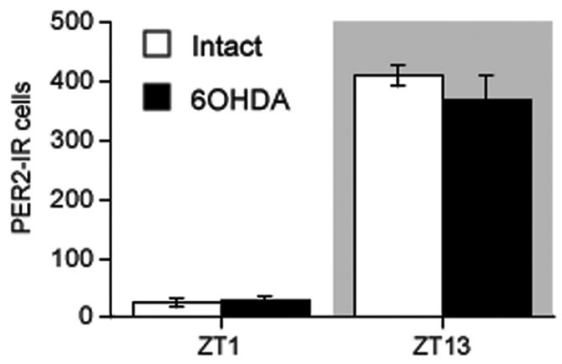

f SKF

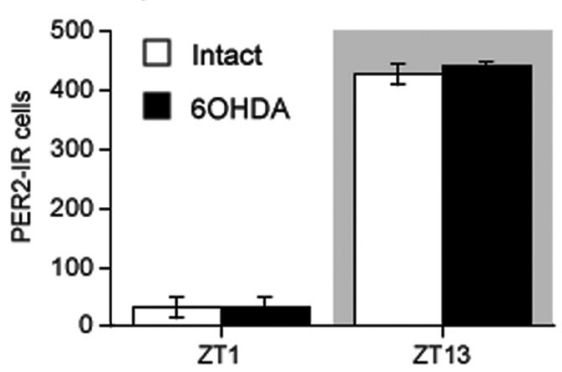

Wheel running

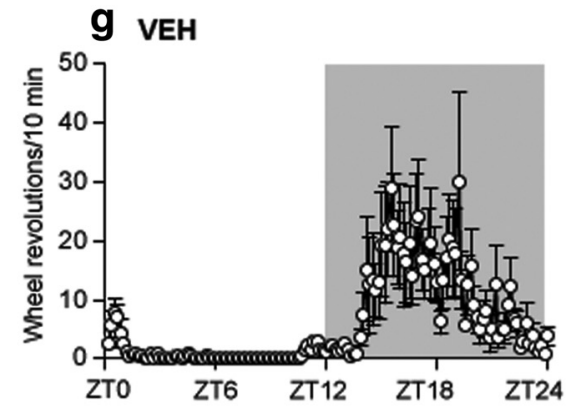

h QUIN

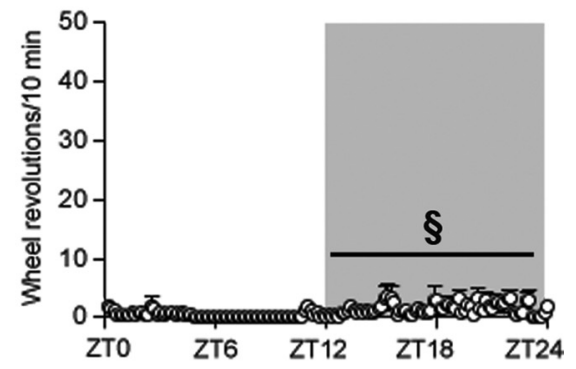

i SKF

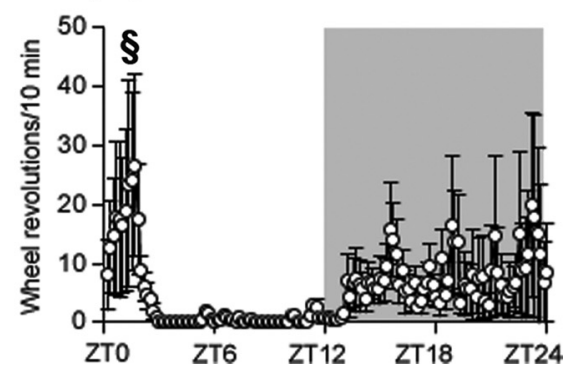

Figure 11. PER2 expression in the dorsal striatum and SCN and daily wheel-running activity in 6-OHDA-lesioned rats injected daily at ZT1 with vehicle (VEH), the $\mathrm{D}_{2 / 3}$ agonist, quinpirole $(0.5$ $\mathrm{mg} / \mathrm{kg}$ ), or the D DA agonist, SKF $81297(1 \mathrm{mg} / \mathrm{kg})$. In the dorsal striatum $(\boldsymbol{a}-\boldsymbol{c})$, daytime PER2 expression was decreased on the 6-OHDA-lesioned side in vehicle-injected rats $(\boldsymbol{a})$ (expressed as mean PER2-IR \pm SEM at each ZT; $n=7-8$ per ZT). Daily injection of quinpirole $(\boldsymbol{b})$ selectively increased PER2 expression at ZT13 in the dorsal striatum of the 6-0HDA-lesioned hemisphere ( $n=6$ per ZT), whereas daily injection of SKF 81297 (c) had no effect on PER2 in either the lesioned or intact hemisphere ( $n=3$ per ZT). PER2 expression in the SCN was not affected by any of these treatments $(\boldsymbol{d}-\boldsymbol{f})$. The normal $24 \mathrm{~h}$ rhythm in wheel running during the $10 \mathrm{~d}$ injection period $(\boldsymbol{g}-\boldsymbol{i})$ was not disrupted by daily vehicle injection $(\boldsymbol{g})$ (expressed as mean wheel revolutions/10 min bin over $24 \mathrm{~h} \pm$ SEM; $n=15)$. Quinpirole injection $(\boldsymbol{h})$ suppressed nighttime wheel running $(n=12)$, whereas SKF 81297 injection (i) increased daytime wheel running $(n=6)$, particularly in the hour before the injection was given (ZT0 -ZT1). ${ }^{*}$ Significant difference from the intact hemisphere; ${ }^{* *}$ significant difference from vehicle group lesioned hemisphere, $p<0.05 ;{ }^{\S}$ significant difference from the vehicle group, $p<0.05$.

Mechanisms of PER2 modulation by DA in the dorsal striatum

The mechanisms whereby DA depletion and $\mathrm{D}_{2}$ DA receptor activation suppress and restore, respectively, PER2 expression in the striatum remain to be resolved. It is clear that changes in locomotor activity brought about by DA depletion or, indeed, by $\mathrm{D}_{2}$ DA receptor stimulation cannot explain the changes in PER2 expression. Unilateral depletion of striatal DA, which strongly blunted the rhythm of PER2 expression on the lesioned side, did not disrupt the daily activity rhythm even though the level of nighttime activity was reduced. Furthermore, daily quinpirole injections restored the daily variation of PER2 expression in the lesioned striatum while suppressing nighttime activity, but had no effect on PER2 expression in the intact hemisphere.

The absence of an effect of quinpirole injections on the PER2 rhythm in the intact striatum and in the striatum of naive rats is likely attributable to the time of day when injections were given. The dose of quinpirole used in the present experiments has been shown to reliably inhibit the activity of DA neurons in naive rats through activation of $\mathrm{D}_{2}$ DA autoreceptors on DA cell bodies (Lacey et al., 1987; Jeziorski and White, 1989). Indeed, we have found that similar injections of quinpirole in naive rats at the start of the dark phase, when extracellular DA levels in the striatum are beginning to rise, strongly reduce the normal striatal peak of PER2 expression at ZT1 (our unpublished observations). Because quinpirole injections were given at ZT1 in the present experiments, during the trough of the rhythm of extracellular DA, an additional reduction in dopaminergic cell activity at this time of day would have little impact on the normal PER2 rhythm. After a 6-OHDA lesion, however, the expression of $\mathrm{D}_{2}$ DA receptors on cell bodies is lost through destruction of DA fibers, whereas postsynaptic expression of $\mathrm{D}_{2}$ DA receptors in medium spiny neurons is upregulated (Gerfen et al., 1990). Thus, the 6-OHDA-lesioned hemisphere would be highly sensitive to $D_{2}$ DA receptor stimulation.

Our RT-PCR results suggest that a normal fluctuation in extracellular DA is necessary for the transcription of Per2 in the dorsal striatum. These results corroborate those of Sahar et al. 

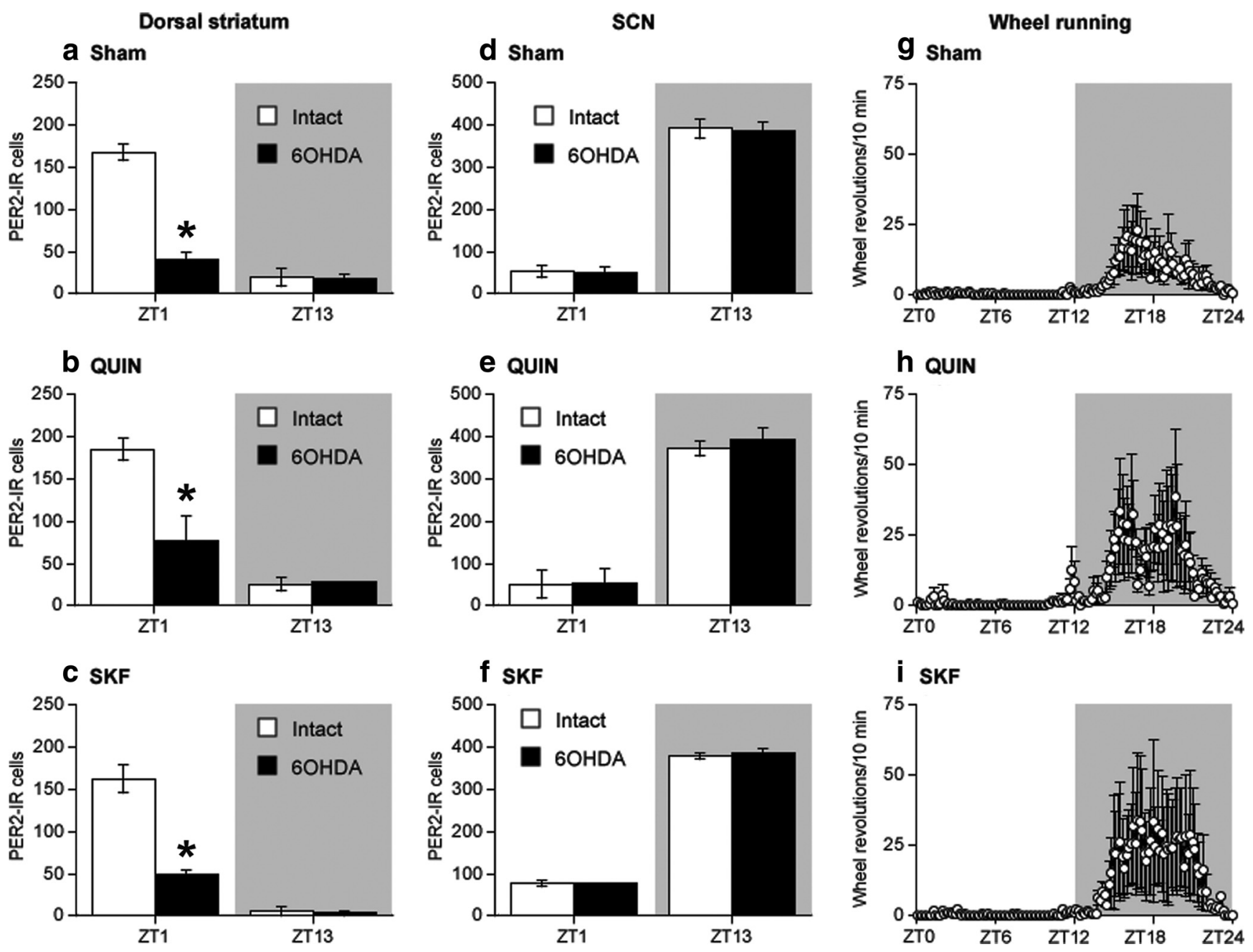

Figure 12. Continuous infusion of the $D_{2 / 3}$ agonist, quinpirole $\left(0.5 \mathrm{mg} \cdot \mathrm{kg}^{-1} \cdot 24 \mathrm{~h}^{-1} ; n=2-3\right.$ per ZT), or the $D_{1}$ DA agonist, SKF $81297\left(1 \mathrm{mg} \cdot \mathrm{kg}{ }^{-1} \cdot \mathrm{d}^{-1} ; n=2-3\right.$ per $\left.Z \mathrm{ZT}\right)$, for $10 \mathrm{~d}$ via osmotic minipump has no effect on mean ( \pm SEM) PER2 expression in either the 6-0HDA-lesioned or intact dorsal striatum $(\boldsymbol{b}, \boldsymbol{c})$ or SCN $(\boldsymbol{e}, \boldsymbol{f})$ compared with sham surgery group $(\boldsymbol{a}, \boldsymbol{d})(\boldsymbol{n}=3-5$ perZT). Neither treatment affected daily wheel-running activity (expressed as mean wheel revolutions $/ 10$ min bin over $24 \mathrm{~h} \pm$ SEM) $(\boldsymbol{g}-\boldsymbol{i})$. ${ }^{*}$ Significant difference from intact hemisphere, $p<0.05$.

(2010) who reported a decrease in the amplitude of the Per2 transcription rhythm in the striatum of $\mathrm{D}_{2}$ knock-out mice. The question then remains, how might activation of $\mathrm{D}_{2}$ DA receptors regulate the rhythm of PER2 expression in the striatum? Together, these results support the idea that $\mathrm{D}_{2}$ signaling modulates PER2 expression at the level of transcription. This modulation could occur through the CAMP-CREB signaling pathway, which is regulated by DA signaling (Montmayeur and Borrelli, 1991). The Per2 promoter region contains a CRE-responsive site (TravnickovaBendova et al., 2002) and $\mathrm{D}_{2}$ receptor stimulation upregulates Per expression in the retina through a CREB-dependent mechanism (Besharse et al., 2004; Yujnovsky et al., 2006). It is possible, however, that DA regulates PER2 expression directly through changes in posttranslational phosphorylation mechanisms (Iitaka et al., 2005) or indirectly by modulating other components of the clock (Beaulieu et al., 2004; Sahar et al., 2010).

A different possibility is that DA acts via presynaptic $\mathrm{D}_{2} \mathrm{DA}$ receptors to affect PER2 expression by modulating the activity of corticostriatal glutamatergic neurons (Bamford et al., 2004) or the effect of glutamate on $\mathrm{D}_{2}$ DA receptor-expressing striatopallidal neurons (for review, see Surmeier et al., 2007). Glutamate plays a key role in clock gene expression in the SCN (Reppert and Weaver, 2001) and after 6-OHDA lesions of DA inputs to the striatum there are changes in both glutamate release and respon- siveness of $\mathrm{D}_{2}$ DA receptor-bearing striatopallidal neurons to glutamate (Day et al., 2006). These changes in glutamate transmission could be linked in as-yet-unknown ways to changes in expression of PER2 in these striatal neurons.

Alternatively, our results leave open a role for NA in the modulation of PER2 expression in the dorsal striatum. AMPT depletion of catecholamines strongly reduced PER2 expression in this region, as well as in $\mathrm{M} 1$ and DG, which receive NA inputs. Manipulation of catecholaminergic activity, and specifically NA, might indirectly regulate the expression of PER2 in the dorsal striatum by modulating the activity of corticostriatal projections to the striatum. We are currently examining the impact of cortical lesions on striatal PER2 expression.

\section{DA does not regulate PER2 in the SCN}

In all our experiments, we assessed PER2 expression in the SCN. Without exception, no changes in PER2 expression were found either after DA depletion or activation/blockade of DA receptors. This insensitivity of the SCN is consistent with previous reports that the adult SCN, unlike the fetal SCN (Weaver et al., 1992; Schurov et al., 2002), is impervious to dopaminergic manipulations (Duffield et al., 1998; Masubuchi et al., 2000) and is consistent with our finding that dopaminergic manipulations did not affect the daily rhythm of locomotor activity. 


\section{Functional significance of PER2 regulation by DA}

Finally, it is interesting to speculate about the role of clock genes in functions mediated by the striatum. One idea is that clock genes, including Per2, play a role in the modulation of reward processes known to involve dopaminergic activity in the striatum (Abarca et al., 2002; McClung et al., 2005; Roybal et al., 2007). This is supported by the evidence that Per2 mutant mice exhibit greater responsivity to cocaine (Abarca et al., 2002), drink more alcohol, and have higher levels of extracellular glutamate in the brain secondary to reduced glutamate uptake (Spanagel et al., 2005). Another idea, directly related to the present findings, is that the loss of circadian rhythms in clock gene expression in the striatum after DA depletion is linked to disruptions of daily behavioral and physiological rhythms frequently reported in Parkinson's disease (Bruguerolle and Simon, 2002; Cai et al., 2010). Current models posit that the symptoms of Parkinson's disease result from changes in excitability of striatopallidal neurons secondary to depletion of striatal DA (Day et al., 2006). Our findings that loss of striatal DA can disrupt the rhythm of PER2, an essential component of the circadian clock, and that PER2 is regulated by $\mathrm{D}_{2}$ DA receptor activity may provide a clue to understanding the origins of the circadian symptoms of the disease.

\section{References}

Abarca C, Albrecht U, Spanagel R (2002) Cocaine sensitization and reward are under the influence of circadian genes and rhythm. Proc Natl Acad Sci U S A 99:9026-9030.

Abe M, Herzog ED, Yamazaki S, Straume M, Tei H, Sakaki Y, Menaker M, Block GD (2002) Circadian rhythms in isolated brain regions. J Neurosci 22:350-356.

Amir S, Stewart J (2009) Motivational modulation of rhythms of the expression of the clock protein PER2 in the limbic forebrain. Biol Psychiatry 65:829-834.

Amir S, Lamont EW, Robinson B, Stewart J (2004) A circadian rhythm in the expression of PERIOD2 protein reveals a novel SCN-controlled oscillator in the oval nucleus of the bed nucleus of the stria terminalis. J Neurosci 24:781-790.

Amir S, Harbour VL, Robinson B (2006) Pinealectomy does not affect diurnal PER2 expression in the rat limbic forebrain. Neurosci Lett 399:147-150.

Angeles-Castellanos M, Mendoza J, Escobar C (2007) Restricted feeding schedules phase shift daily rhythms of c-Fos and protein Per1 immunoreactivity in corticolimbic regions in rats. Neuroscience 144:344-355.

Anstrom KK, Schallert T, Woodlee MT, Shattuck A, Roberts DC (2007) Repetitive vibrissae-elicited forelimb placing before and immediately after unilateral 6-hydroxydopamine improves outcome in a model of Parkinson's disease. Behav Brain Res 179:183-191.

Asan E (1998) The catecholaminergic innervation of the rat amygdala. Adv Anat Embryol Cell Biol 142:1-118.

Ballion B, Frenois F, Zold CL, Chetrit J, Murer MG, Gonon F (2009) $D_{2}$ receptor stimulation, but not $D_{1}$, restores striatal equilibrium in a rat model of Parkinsonism. Neurobiol Dis 35:376-384.

Bamford NS, Zhang H, Schmitz Y, Wu NP, Cepeda C, Levine MS, Schmauss C, Zakharenko SS, Zablow L, Sulzer D (2004) Heterosynaptic dopamine neurotransmission selects sets of corticostriatal terminals. Neuron 42:653-663.

Beaulieu JM, Sotnikova TD, Yao WD, Kockeritz L, Woodgett JR, Gainetdinov RR, Caron MG (2004) Lithium antagonizes dopamine-dependent behaviors mediated by an AKT/glycogen synthase kinase 3 signaling cascade. Proc Natl Acad Sci U S A 101:5099-5104.

Besharse JC, Zhuang M, Freeman K, Fogerty J (2004) Regulation of photoreceptor Per1 and Per2 by light, dopamine and a circadian clock. Eur J Neurosci 20:167-174.

Bruguerolle B, Simon N (2002) Biologic rhythms and Parkinson's disease: a chronopharmacologic approach to considering fluctuations in function. Clin Neuropharmacol 25:194-201.

Cai Y, Liu S, Sothern RB, Xu S, Chan P (2010) Expression of clock genes Perl and Bmal1 in total leukocytes in health and Parkinson's disease. Eur J Neurol 17:550-554.
Castañeda TR, de Prado BM, Prieto D, Mora F (2004) Circadian rhythms of dopamine, glutamate and GABA in the striatum and nucleus accumbens of the awake rat: modulation by light. J Pineal Res 36:177-185.

Chen R, Schirmer A, Lee Y, Lee H, Kumar V, Yoo SH, Takahashi JS, Lee C (2009) Rhythmic PER abundance defines a critical nodal point for negative feedback within the circadian clock mechanism. Mol Cell 36: 417-430.

Creese I, Chen A (1985) Selective D-1 dopamine receptor increase following chronic treatment with SCH 23390. Eur J Pharmacol 109:127-128.

Day M, Wang Z, Ding J, An X, Ingham CA, Shering AF, Wokosin D, Ilijic E, Sun Z, Sampson AR, Mugnaini E, Deutch AY, Sesack SR, Arbuthnott GW, Surmeier DJ (2006) Selective elimination of glutamatergic synapses on striatopallidal neurons in Parkinson disease models. Nat Neurosci 9: 251-259.

Doi M, Yujnovsky I, Hirayama J, Malerba M, Tirotta E, Sassone-Corsi P, Borrelli E (2006) Impaired light masking in dopamine $\mathrm{D}_{2}$ receptor-null mice. Nat Neurosci 9:732-734.

Duffield GE, Hastings MH, Ebling FJ (1998) Investigation into the regulation of the circadian system by dopamine and melatonin in the adult Siberian hamster (Phodopus sungorus). J Neuroendocrinol 10:871-884.

Fallon JH, Koziell DA, Moore RY (1978) Catecholamine innervation of the basal forebrain. II. Amygdala, suprarhinal cortex and entorhinal cortex. J Comp Neurol 180:509-532.

Field MD, Maywood ES, O’Brien JA, Weaver DR, Reppert SM, Hastings MH (2000) Analysis of clock proteins in mouse SCN demonstrates phylogenetic divergence of the circadian clockwork and resetting mechanisms. Neuron 25:437-447.

Gerfen CR, Engber TM, Mahan LC, Susel Z, Chase TN, Monsma FJ Jr, Sibley DR (1990) $D_{1}$ and $D_{2}$ dopamine receptor-regulated gene expression of striatonigral and striatopallidal neurons. Science 250:1429-1432.

Gerfen CR, Keefe KA, Gauda EB (1995) $D_{1}$ and $D_{2}$ dopamine receptor function in the striatum: coactivation of $\mathrm{D}_{1}$ - and $\mathrm{D}_{2}$-dopamine receptors on separate populations of neurons results in potentiated immediate early gene response in $\mathrm{D}_{1}$-containing neurons. J Neurosci 15:8167-8176.

Guilding C, Piggins HD (2007) Challenging the omnipotence of the suprachiasmatic timekeeper: are circadian oscillators present throughout the mammalian brain? Eur J Neurosci 25:3195-3216.

Hampp G, Ripperger JA, Houben T, Schmutz I, Blex C, Perreau-Lenz S, Brunk I, Spanagel R, Ahnert-Hilger G, Meijer JH, Albrecht U (2008) Regulation of monoamine oxidase A by circadian-clock components implies clock influence on mood. Curr Biol 18:678-683.

Hastings MH, Field MD, Maywood ES, Weaver DR, Reppert SM (1999) Differential regulation of mPER1 and mTIM proteins in the mouse suprachiasmatic nuclei: new insights into a core clock mechanism. J Neurosci 19:RC11(1-7).

Hu XT, Brooderson RJ, White FJ (1992) Repeated stimulation of $\mathrm{D}_{1}$ dopamine receptors causes time-dependent alterations in the sensitivity of both $\mathrm{D}_{1}$ and $\mathrm{D}_{2}$ dopamine receptors within the rat striatum. Neuroscience 50:137-147.

Iijima M, Nikaido T, Akiyama M, Moriya T, Shibata S (2002) Methamphetamine-induced, suprachiasmatic nucleus-independent circadian rhythms of activity and mPer gene expression in the striatum of the mouse. Eur J Neurosci 16:921-929.

Iitaka C, Miyazaki K, Akaike T, Ishida N (2005) A role for glycogen synthase kinase-3beta in the mammalian circadian clock. J Biol Chem 280:29397-29402.

Imbesi M, Yildiz S, Dirim Arslan A, Sharma R, Manev H, Uz T (2009) Dopamine receptor-mediated regulation of neuronal "clock" gene expression. Neuroscience 158:537-544.

Jeziorski M, White FJ (1989) Dopamine agonists at repeated "autoreceptorselective" doses: effects upon the sensitivity of A10 dopamine autoreceptors. Synapse 4:267-280.

Kapur S, VanderSpek SC, Brownlee BA, Nobrega JN (2003) Antipsychotic dosing in preclinical models is often unrepresentative of the clinical condition: a suggested solution based on in vivo occupancy. J Pharmacol Exp Ther 305:625-631.

Ko CH, Takahashi JS (2006) Molecular components of the mammalian circadian clock. Hum Mol Genet 15:R271-R277.

Lacey MG, Mercuri NB, North RA (1987) Dopamine acts on $\mathrm{D}_{2}$ receptors to increase potassium conductance in neurones of the rat substantia nigra zona compacta. J Physiol 392:397-416.

Lamont EW, Robinson B, Stewart J, Amir S (2005) The central and basolat- 
eral nuclei of the amygdala exhibit opposite diurnal rhythms of expression of the clock protein Period2. Proc Natl Acad Sci U S A 102: $4180-4184$.

Lowrey PL, Takahashi JS (2000) Genetics of the mammalian circadian system: photic entrainment, circadian pacemaker mechanisms, and posttranslational regulation. Annu Rev Genet 34:533-562.

Lynch WJ, Girgenti MJ, Breslin FJ, Newton SS, Taylor JR (2008) Gene profiling the response to repeated cocaine self-administration in dorsal striatum: a focus on circadian genes. Brain Res 1213:166-177.

Masubuchi S, Honma S, Abe H, Ishizaki K, Namihira M, Ikeda M, Honma K (2000) Clock genes outside the suprachiasmatic nucleus involved in manifestation of locomotor activity rhythm in rats. Eur J Neurosci 12:4206-4214.

McClung CA, Sidiropoulou K, Vitaterna M, Takahashi JS, White FJ, Cooper DC, Nestler EJ (2005) Regulation of dopaminergic transmission and cocaine reward by the Clock gene. Proc Natl Acad Sci U S A 102:9377-9381.

Montmayeur JP, Borrelli E (1991) Transcription mediated by a cAMPresponsive promoter element is reduced upon activation of dopamine $\mathrm{D}_{2}$ receptors. Proc Natl Acad Sci U S A 88:3135-3139.

Moroz IA, Peciña S, Schallert T, Stewart J (2004) Sparing of behavior and basal extracellular dopamine after 6-hydroxydopamine lesions of the nigrostriatal pathway in rats exposed to a prelesion sensitizing regimen of amphetamine. Exp Neurol 189:78-93.

Neisewander JL, Fuchs RA, O’Dell LE, Khroyan TV (1998) Effects of SCH23390 on dopamine $\mathrm{D}_{1}$ receptor occupancy and locomotion produced by intraaccumbens cocaine infusion. Synapse 30:194-204.

Nikaido T, Akiyama M, Moriya T, Shibata S (2001) Sensitized increase of period gene expression in the mouse caudate/putamen caused by repeated injection of methamphetamine. Mol Pharmacol 59:894-900.

Paulson PE, Robinson TE (1994) Relationship between circadian changes in spontaneous motor activity and dorsal versus ventral striatal dopamine neurotransmission assessed with on-line microdialysis. Behav Neurosci 108:624-635.

Perrin JS, Segall LA, Harbour VL, Woodside B, Amir S (2006) The expression of the clock protein PER2 in the limbic forebrain is modulated by the estrous cycle. Proc Natl Acad Sci U S A 103:5591-5596.

Reppert SM, Weaver DR (2001) Molecular analysis of mammalian circadian rhythms. Annu Rev Physiol 63:647-676.

Roybal K, Theobold D, Graham A, DiNieri JA, Russo SJ, Krishnan V, Chakravarty S, Peevey J, Oehrlein N, Birnbaum S, Vitaterna MH, Orsulak P, Takahashi JS, Nestler EJ, Carlezon WA Jr, McClung CA (2007) Mania-like behavior induced by disruption of CLOCK. Proc Natl Acad Sci U S A 104:6406-6411.

Sahar S, Zocchi L, Kinoshita C, Borrelli E, Sassone-Corsi P (2010) Regulation of BMAL1 protein stability and circadian function by GSK3betamediated phosphorylation. PLoS One 5:e8561.

Samaha AN, Reckless GE, Seeman P, Diwan M, Nobrega JN, Kapur S (2008) Less is more: antipsychotic drug effects are greater with transient rather than continuous delivery. Biol Psychiatry 64:145-152.

Schurov IL, Hepworth TJ, Hastings MH (2002) Dopaminergic signalling in the rodent neonatal suprachiasmatic nucleus identifies a role for protein kinase $\mathrm{A}$ and mitogen-activated protein kinase in circadian entrainment. Eur J Neurosci 15:223-232.

Segall LA, Perrin JS, Walker CD, Stewart J, Amir S (2006) Glucocorticoid rhythms control the rhythm of expression of the clock protein, Period2, in oval nucleus of the bed nucleus of the stria terminalis and central nucleus of the amygdala in rats. Neuroscience 140:753-757.

Shieh KR (2003) Distribution of the rhythm-related genes rPERIOD1, rPERIOD2, and rCLOCK, in the rat brain. Neuroscience 118:831-843.
Sorge RE, Rajabi H, Stewart J (2005) Rats maintained chronically on buprenorphine show reduced heroin and cocaine seeking in tests of extinction and drug-induced reinstatement. Neuropsychopharmacology 30: 1681-1692.

Spanagel R, Pendyala G, Abarca C, Zghoul T, Sanchis-Segura C, Magnone MC, Lascorz J, Depner M, Holzberg D, Soyka M, Schreiber S, Matsuda F Lathrop M, Schumann G, Albrecht U (2005) The clock gene Per2 influences the glutamatergic system and modulates alcohol consumption. Nat Med 11:35-42.

Surmeier DJ, Ding J, Day M, Wang Z, Shen W (2007) $\mathrm{D}_{1}$ and $\mathrm{D}_{2}$ dopaminereceptor modulation of striatal glutamatergic signaling in striatal medium spiny neurons. Trends Neurosci 30:228-235.

Swanson LW, Hartman BK (1975) The central adrenergic system. An immunofluorescence study of the location of cell bodies and their efferent connections in the rat utilizing dopamine-beta-hydroxylase as a marker. J Comp Neurol 163:467-505.

Takahashi S, Yokota S, Hara R, Kobayashi T, Akiyama M, Moriya T, Shibata S (2001) Physical and inflammatory stressors elevate circadian clock gene mPerl mRNA levels in the paraventricular nucleus of the mouse. Endocrinology 142:4910-4917.

Tillerson JL, Caudle WM, Reverón ME, Miller GW (2003) Exercise induces behavioral recovery and attenuates neurochemical deficits in rodent models of Parkinson's disease. Neuroscience 119:899-911.

Travnickova-Bendova Z, Cermakian N, Reppert SM, Sassone-Corsi P (2002) Bimodal regulation of mPeriod promoters by CREB-dependent signaling and CLOCK/BMAL1 activity. Proc Natl Acad Sci U S A 99:7728-7733.

Uz T, Ahmed R, Akhisaroglu M, Kurtuncu M, Imbesi M, Dirim Arslan A, Manev H (2005) Effect of fluoxetine and cocaine on the expression of clock genes in the mouse hippocampus and striatum. Neuroscience 134:1309-1316.

Verwey M, Amir S (2009) Food-entrainable circadian oscillators in the brain. Eur J Neurosci 30:1650-1657.

Verwey M, Lam GY, Amir S (2009) Circadian rhythms of PERIOD1 expression in the dorsomedial hypothalamic nucleus in the absence of entrained food-anticipatory activity rhythms in rats. Eur J Neurosci 29:2217-2222.

Wadenberg ML, Soliman A, VanderSpek SC, Kapur S (2001) Dopamine $\mathrm{D}_{2}$ receptor occupancy is a common mechanism underlying animal models of antipsychotics and their clinical effects. Neuropsychopharmacology 25:633-641.

Wakamatsu H, Yoshinobu Y, Aida R, Moriya T, Akiyama M, Shibata S (2001) Restricted-feeding-induced anticipatory activity rhythm is associated with a phase-shift of the expression of mPer1 and mPer2 mRNA in the cerebral cortex and hippocampus but not in the suprachiasmatic nucleus of mice. Eur J Neurosci 13:1190-1196.

Watson RE Jr, Wiegand SJ, Clough RW, Hoffman GE (1986) Use of cryoprotectant to maintain long-term peptide immunoreactivity and tissue morphology. Peptides 7:155-159.

Weaver DR, Rivkees SA, Reppert SM (1992) $D_{1}$-dopamine receptors activate $\mathrm{c}$-fos expression in the fetal suprachiasmatic nuclei. Proc Natl Acad Sci U S A 89:9201-9204.

Yujnovsky I, Hirayama J, Doi M, Borrelli E, Sassone-Corsi P (2006) Signaling mediated by the dopamine $\mathrm{D}_{2}$ receptor potentiates circadian regulation by CLOCK:BMAL1. Proc Natl Acad Sci U S A 103:6386-6391.

Zhang H, Ma L, Wang F, Chen J, Zhen X (2007) Chronic SKF83959 induced less severe dyskinesia and attenuated L-DOPA-induced dyskinesia in 6-OHDA-lesioned rat model of Parkinson's disease. Neuropharmacology 53:125-133. 